\title{
(1)
}

UNIVERSIDAD PERUANA DE CIENCIAS APLICADAS

FACULTAD DE INGENIERÍA

PROGRAMA DE INGENIERÍA DE SISTEMAS DE INFORMACIÓN

\section{TÉCNICAS DE INFERENCIAS, PREDICCIÓN Y MINERÍA DE DATOS}

TESIS

Para optar el título profesional de Ingeniero de Sistemas de Información

\section{AUTORES}

Apolaya Torres, Carlos Humberto (0000-0002-4867-3058)

Espinosa Diaz, Adolfo (0000-0001-9803-6084)

\section{ASESOR}

Pérez Pichis, Roy (0000-0003-0609-0257) 


\section{Resumen Ejecutivo}

En el primer capítulo, se describe la problemática que se quiere solucionar y se detalla los objetivos específicos que aportan al cumplimiento del objetivo general y el alcance del proyecto.

En el segundo capítulo, se definen los conceptos básicos más importantes como Data Mining y Machine Learning, los cuales están relacionados al tema de estudio de la investigación.

En el tercer capítulo, se encuentra el Estado del Arte, en el cual se revisará la investigación previa relacionada al proyecto indicando el rubro en el que fue implementado. Esto permite entender cómo se encuentra el tema investigado en la actualidad y tener una visión más clara de lo que se puede desarrollar.

En el cuarto capítulo, se describe el desarrollo del proyecto, la metodología a utilizar, se detalla las fases de dicha metodología y el proceso a seguir para la correcta implementación del modelo utilizando arboles de decisión y la metodología Knowledge Discovery in Databases (KDD).

En el quinto capítulo se detalla cómo se obtuvo un porcentaje de error de predicción de aproximadamente $9.13 \%$, las pruebas realizadas y recomendaciones. Así como también las propuestas de continuidad del proyecto enfocados en la mejora del modelo de predicción. Finalmente, en el sexto capítulo se describen los resultados finales en la gestión propia del proyecto, en los aspectos de Resultado Final y las Gestiones de alcance, tiempo, comunicación, recursos humanos y riesgos.

Palabras Clave - Minería de Datos, Aprendizaje por Computadora, Algoritmo de árboles de decisión, Descubrimiento de Conocimiento en Bases de Datos, Validación Cruzada 


\begin{abstract}
In the first chapter, it describes the problem to be solved and it details the specific objectives that contribute to the fulfillment of the general objective and the scope of the project. In the second chapter, the most important basic concepts like Data Mining and Machine Learning are defined, which are related to the subject of research study.

In the third chapter, there is the State of Art, in which the previous research related to the project will be reviewed indicating the area in which it was implemented. This allows us to understand how the subject is currently investigated and to have a clearer vision of what can be developed.
\end{abstract}

In the fourth chapter, we describe the development of the project, the methodology to be used, details the phases of the methodology and the process to be followed for the correct implementation of the model using decision trees and the Knowledge Discovery in Databases (KDD) methodology.

The fifth chapter details how we obtained a prediction error rate of approximately $9.13 \%$, the tests performed and recommendations. As well as proposals for project continuity focused on improving the prediction model.

Finally in the sixth chapter, the final results are described in the project's own management, in the aspects of Final Result and the Outreach, Time, Communication, Human Resources and Risk Management.

Keywords - Data Mining, Machine Learning, Decision Tree Algorithm, Knowledge Discovery in Databases, Cross-Validation. 


\section{Tabla de Contenidos}

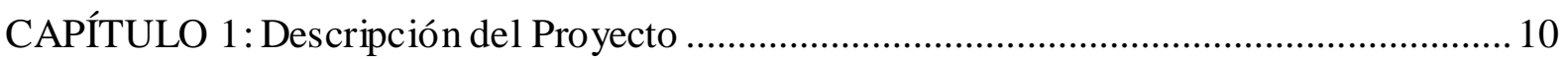

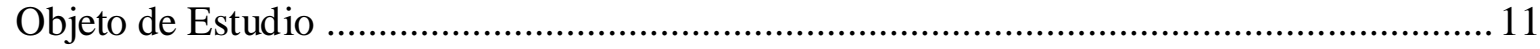

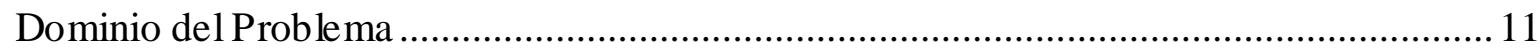

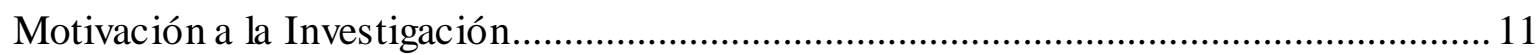

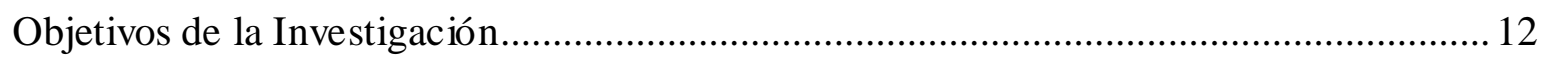

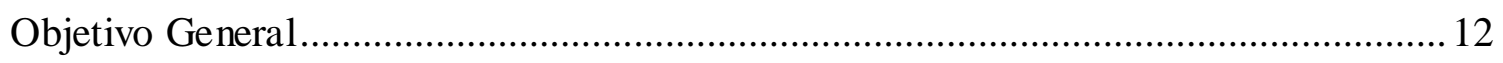

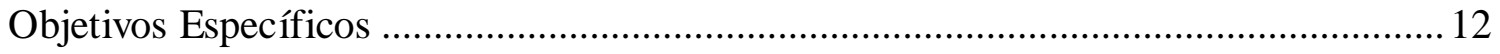

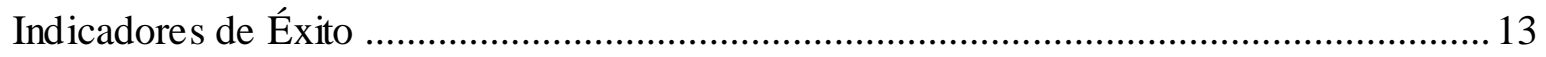

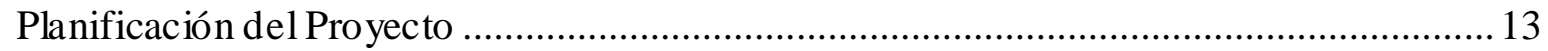

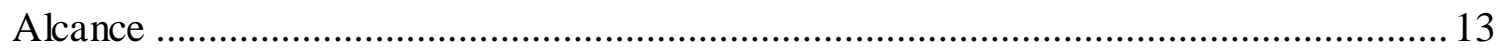

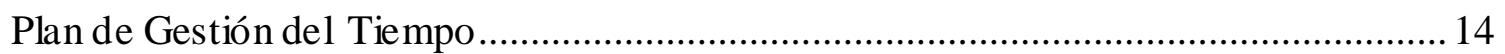

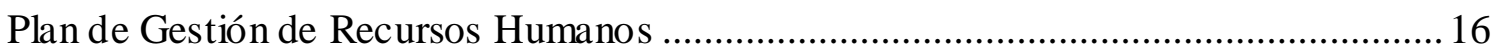

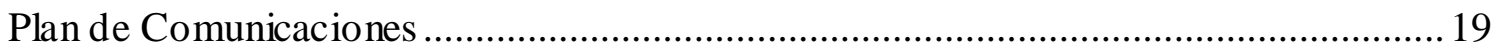

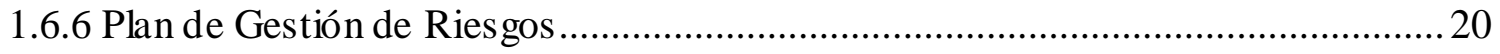

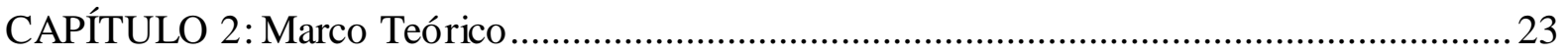

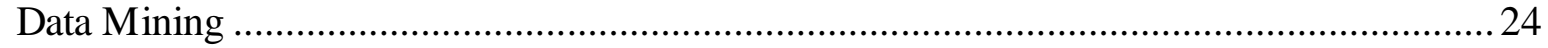

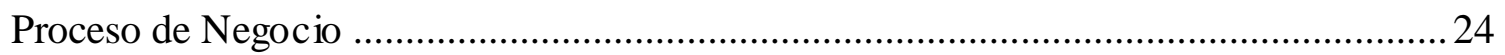

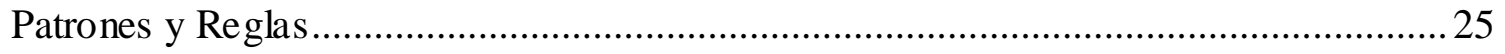

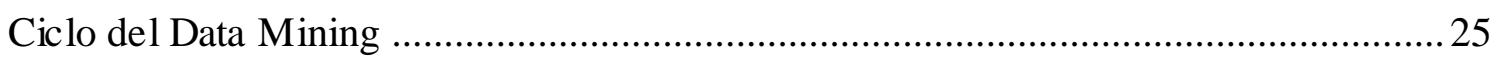

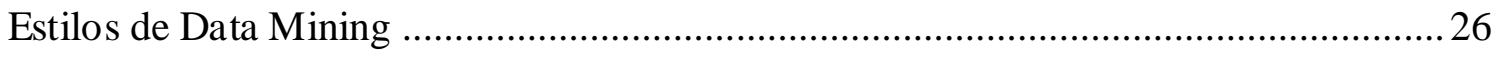

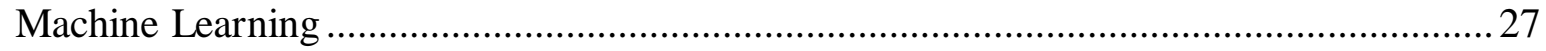

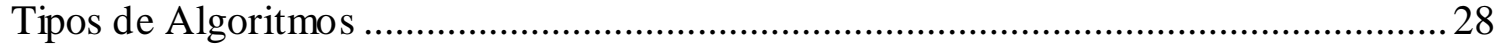

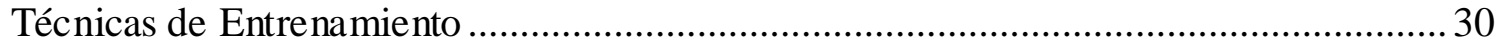

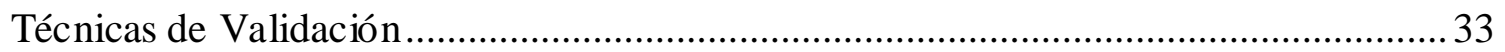

Cuadro comparativo entre Machine Learning y Data Mining ....................................... 37

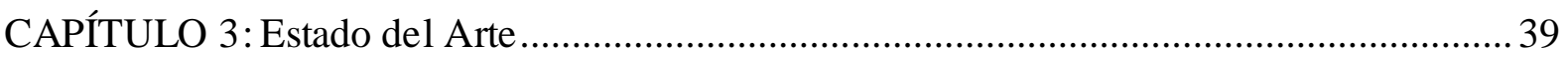

Resumen de los casos de éxito en la implementación de Data Mining .............................. 40

Recommendation in Highter Education Using Data Mining Techniques (2009) ............ 40

A case Study: Data Mining Applied to Student Enrollment (2010) …............................ 42 
Data Mining Applications: A comparative Study for Predicting Student's performance (2012)

Mining Student Data Using Decision Trees (2006)

Uncovering Hidden Information within University's Student Enrollment Data Using Data Mining (2009)

A Data Mining Approach to Recommend Learning Paths based on Academic Performance 44

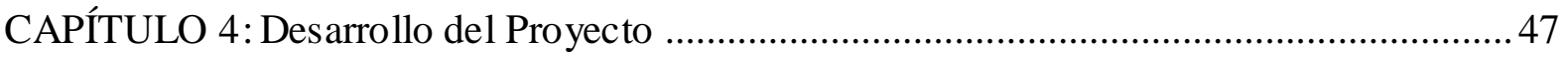

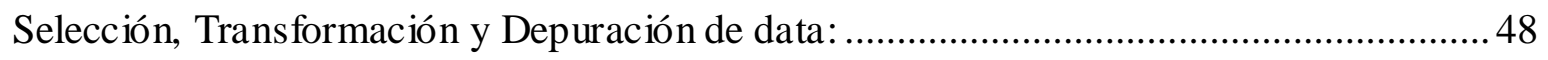

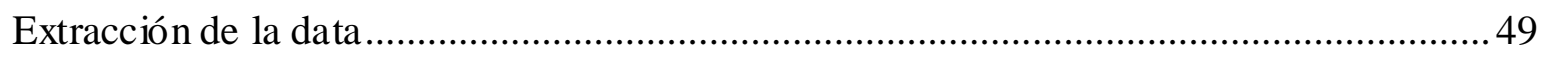

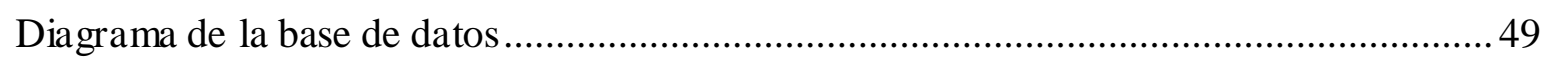

Depuración, Selección y Transformación de data .......................................................50

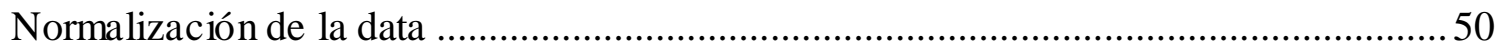

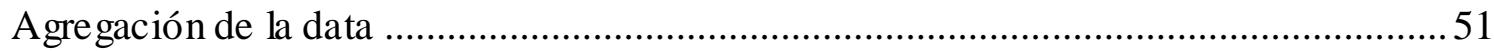

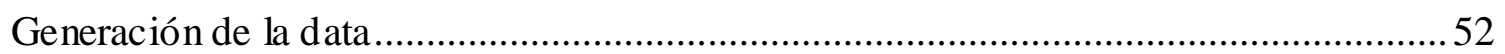

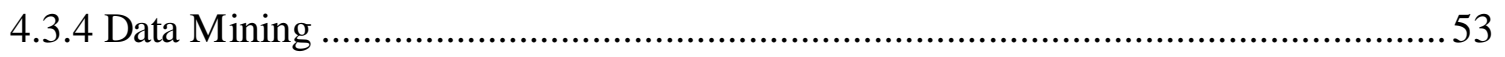

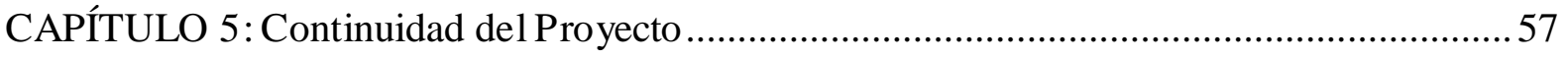

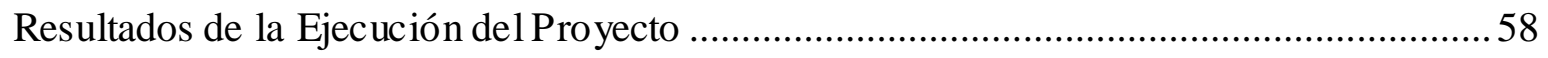

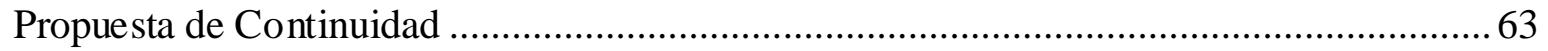

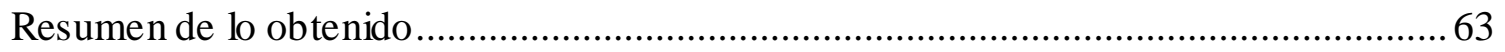

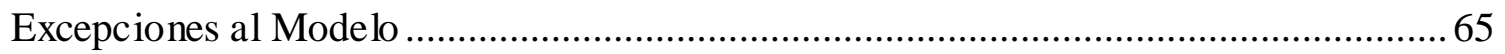

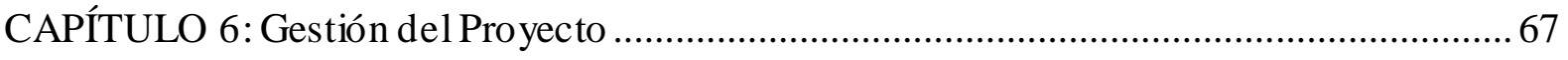

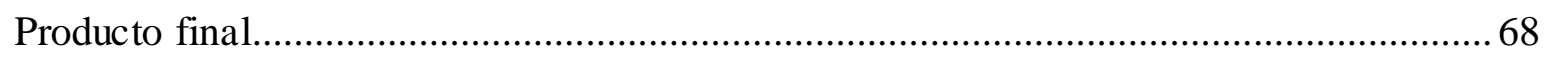

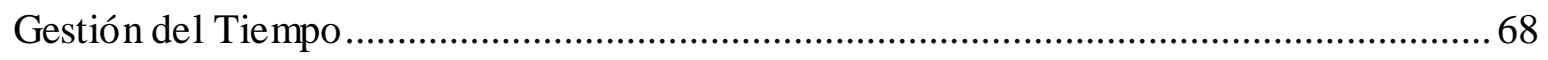

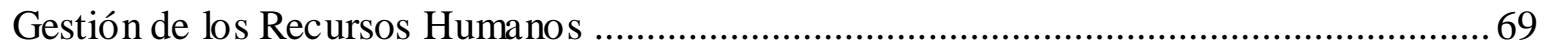

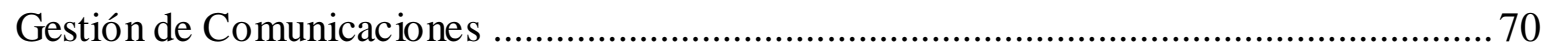

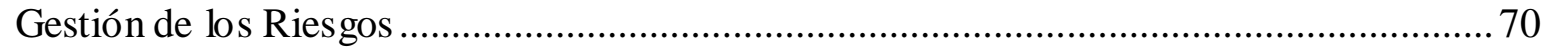

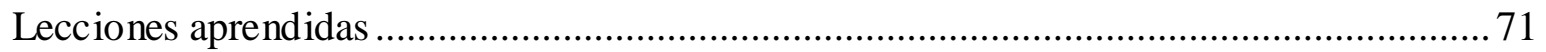

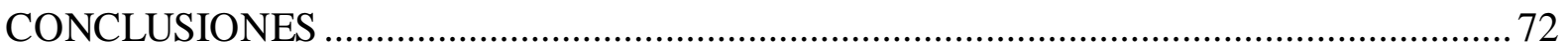

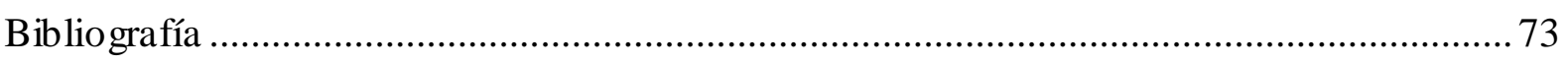




\section{Listado de Ilustraciones}

Ilustración 1: Estructura organizacional del proyecto - Ciclo 2014-II.................................... 16

Ilustración 2: Guía de almacenamiento de documentos - MINDATA ONEDRIVE ...............20

Ilustración 3: Ciclo de Vida de Data Mining ....................................................................... 26

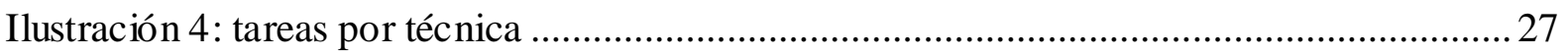

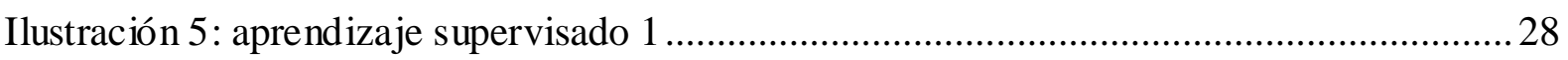

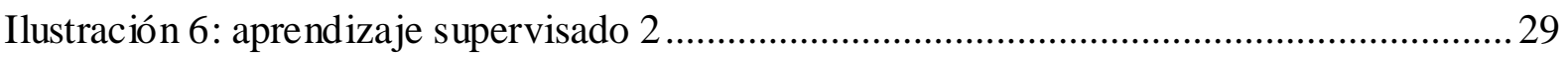

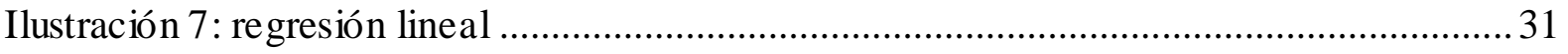

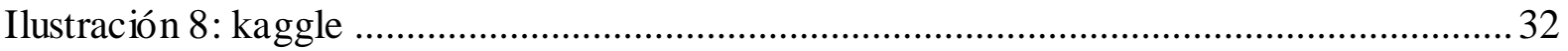

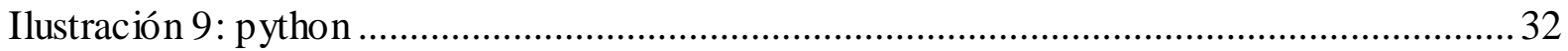

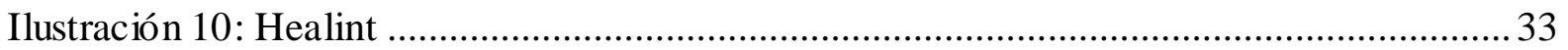

Ilustración 11 Arquitectura del sistema de recomendación ................................................. 41

Ilustración 12 Diagrama de flujo del sistema de recomendación ........................................... 42

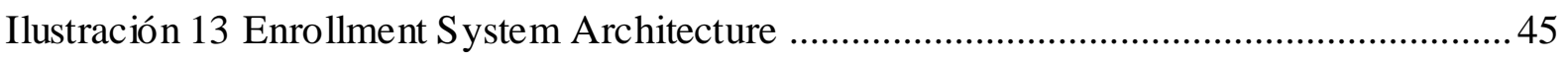

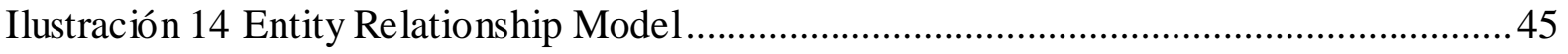

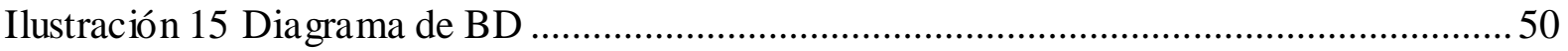

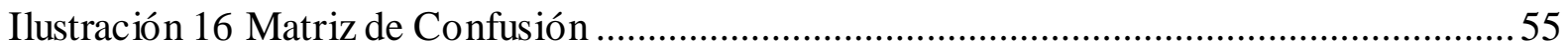

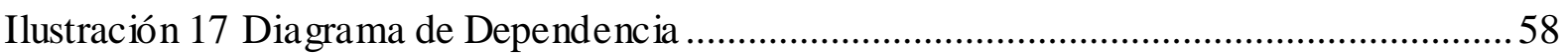

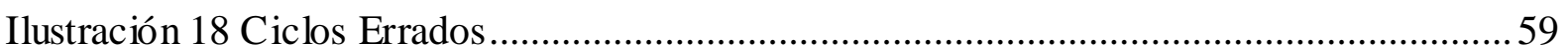

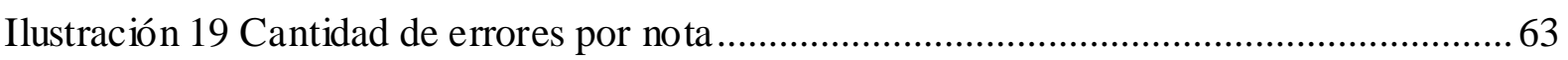




\section{Listado de Tablas}

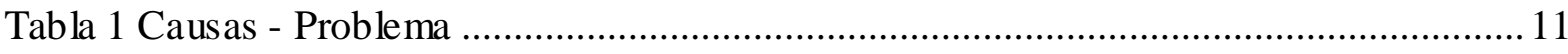

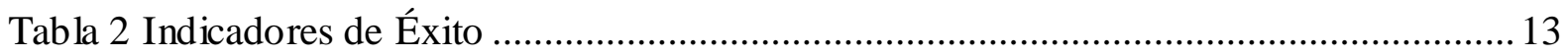

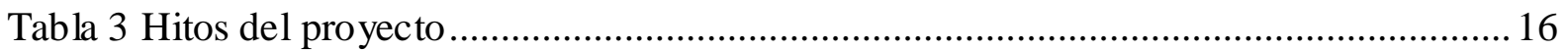

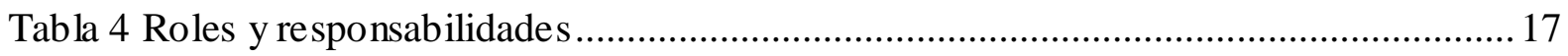

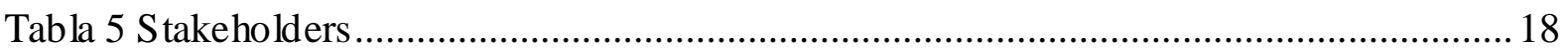

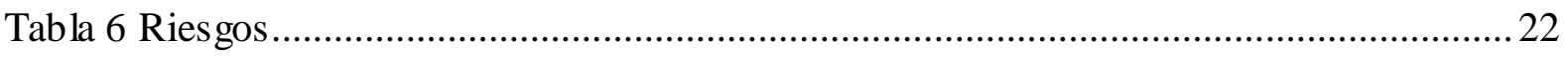

Tabla 7 Diferencias DM y ML-Fuente: Elaboración Propia ................................................... 38

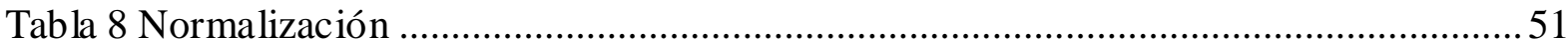

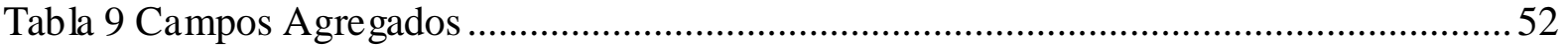

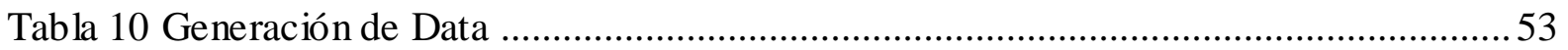

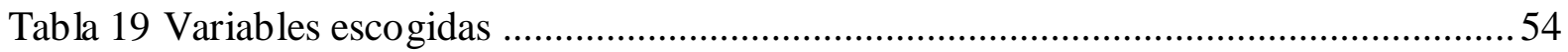

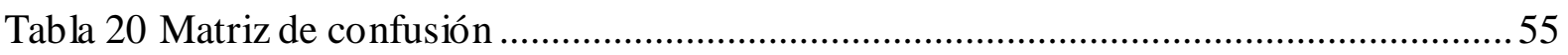

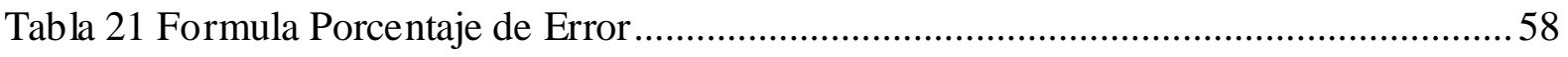

Tabla 22 Resultados Matriz de Confusión...........................................................................59

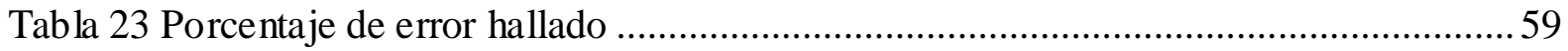

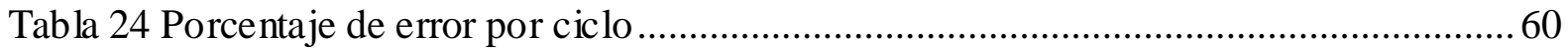

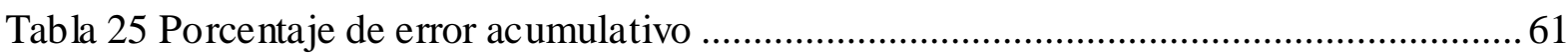

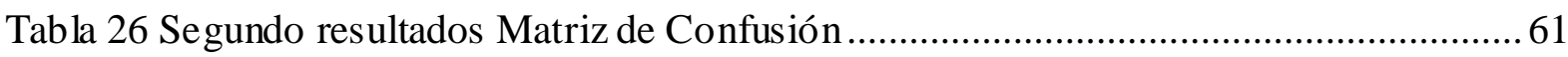

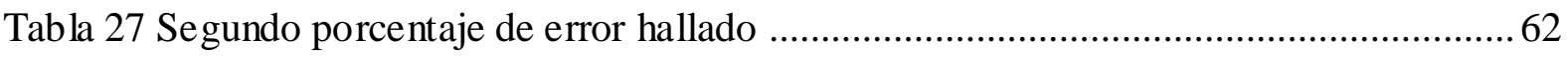

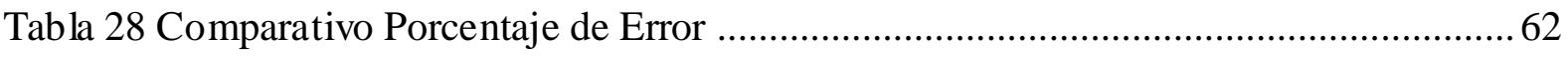

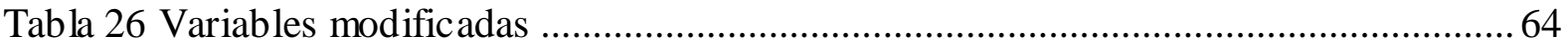

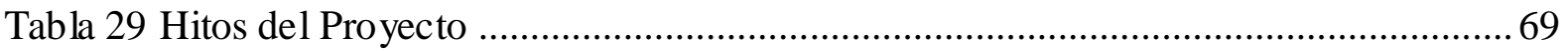




\section{Introducción}

Es muy frecuente escuchar el término Data Mining o minería de datos, pues se usa para descubrir patrones en grandes volúmenes de datos que en la actualidad son necesarios para tomar decisiones dado que el uso de internet, redes sociales, almacenamiento en la nube, se encuentran en auge. Para lograr analizar la data generada día a día, se utilizan técnicas de Data Mining que ayudan a encontrar patrones que no se lograría de otra forma.

No solo es aplicado al estudio de datos en las redes sociales, sino también en diferentes rubros como lo son la seguridad ciudadana, medicina, ventas, etc. Uno de estos rubros es la educación, en la cual va creciendo la demanda por centros de estudios, ya que en la sociedad peruana tener estudios superiores es la forma más viable para conseguir una mejor forma de vida. Y dado la gran competencia del mercado limeño en el que todas las universidades quieren captar la mayor cantidad de alumnos con sus propuestas en las currículas de sus carreras, es necesario buscar nuevas mejoras, con herramientas más complejas que ayuden a interpretar los resultados de los alumnos y las tendencias del mercado para lograr sobresalir.

El proyecto será desarrollado en dos ciclos académicos. La primera parte tratará sobre un estudio de las principales técnicas y mecanismos de Machine Learning utilizados para la resolución de Data Mining. Estas técnicas serán evaluadas con la finalidad de documentar las ventajas y desventajas que presentan para cada tipo de dato.

La segunda parte, en base a la información y conocimientos adquiridos, se procederá a clasificar las distintas técnicas de Data Mining con la finalidad de crear una matriz de referencia. Para luego escoger la más adecuada y aplicarla al rubro de la educación superior en la que se planteara un modelo basado en la metodología escogida luego del estudio realizado. Dicho modelo debe cumplir con lo investigado y lograr predecir un resultado con un porcentaje de error menor que los encontrados a lo largo de la investigación.

A lo largo del proyecto se están contemplando los siguientes entregables: Project Charter, un plan de trabajo, paper de investigación, matriz de referencias y memoria del proyecto, los cuales serán evaluados y aprobados por el comité de proyecto y el cliente. 
Por último, en el presente documento están considerados los principales riesgos del proyecto y los planes para mitigarlos. Así como también las suposiciones y restricciones que se están asumiendo en el proyecto.I 


\section{CAPÍTUlO 1: Descripción del Proyecto}

El presente capítulo describe la problemática que se quiere solucionar. Por otro lado, se detalla los objetivos específicos que aportan al cumplimiento del objetivo general y el alcance del proyecto. Finalmente, se presenta los entregables del proyecto, los responsables, la comunicación entre los responsables y los riesgos identificados ordenados por prioridad. 


\section{Objeto de Estudio}

El objetivo de estudio de este proyecto es identificar las principales características de las principales técnicas y metodologías de Data Mining y Machine Learning con el fin de clasificarlas y luego proponer un modelo que pueda ser aplicado al rubro de la educación superior en el Perú. Esto quiere decir que en base a la investigación realizada se podrá elegir que técnica y metodología es la óptima según se necesite.

\section{Dominio del Problema}

El problema de estudio de investigación se logra identificar a partir de las siguientes causas:

\begin{tabular}{|c|c|}
\hline Causas & Problema \\
\hline $\begin{array}{l}\text { Existe un crecimiento de la data que se genera por } \\
\text { cada alumno en la escuela en las diferentes sedes } \\
\text { de la universidad. } \\
\text { Crecimiento exponencial del tiempo de duración } \\
\text { del análisis de la data que se genera cada ciclo. } \\
\text { Poca información de las herramientas y } \\
\text { algoritmos a utilizar en el ámbito de la educación. }\end{array}$ & $\begin{array}{l}\text { El gran volumen de data que se genera } \\
\text { a partir de los alumnos en la Escuela } \\
\text { de Ingeniería de Sistemas y } \\
\text { Computación } \\
\text { exponencialmente. Dicha información } \\
\text { no cuenta con una técnica adecuada } \\
\text { para su análisis, por lo que la toma de } \\
\text { decisiones se dificulta y se vuelve más } \\
\text { compleja la mejora continua de la } \\
\text { escuela. }\end{array}$ \\
\hline
\end{tabular}

Tabla 1 Causas - Problema

Fuente: Elaboración Propia

\section{Motivación a la Investigación}

La educación en el Perú es un negocio, debido a las facilidades que el gobierno dio con el decreto legislativo $N^{\circ} 882$ o la ley de Promoción de la Inversión en la Educación a partir de la década de 1990, para mejorar la economía del país. Desde entonces, las universidades en el país y específicamente en Lima están siempre compitiendo por captar mayor volumen de 
alumnos. Desde el año 2000 la economía mejoró y empezó a ser más rentable el rubro Educación.

En la ciudad de Lima, va creciendo la demanda por centros de estudios, ya que, en la sociedad peruana, contar con estudios superiores es la forma más viable para conseguir una mejor forma de vida. Dada la gran competencia del mercado limeño, en el que todas las universidades quieren captar la mayor cantidad de alumnos con las mallas curriculares de sus carreras, es necesario buscar nuevas mejoras, con herramientas más complejas que ayuden a interpretar los resultados de los alumnos y las tendencias del mercado para lograr sobresalir y poder captar un mayor volumen de alumnos.

\section{Objetivos de la Investigación}

A continuación, se detalla el objetivo general del proyecto y los objetivos específicos que han sido definidos para dar solución del problema identificado.

\section{Objetivo General}

Implementar un modelo de minería de datos que utilice árboles de decisión, orientada al rubro de Educación que le permita una mejor toma de decisiones a la Escuela de Ingeniería de Sistemas y Computación de la UPC.

\section{Objetivos Específicos}

- OE1: Analizar los conceptos, técnicas, herramientas y metodologías relacionadas a Minería de Datos.

- OE2: Diseñar un modelo de Minería de Datos estructurado de acuerdo a la metodología, herramienta y datos obtenidos de la escuela de Ingeniería de Sistemas y Computación de la UPC.

- OE3: Implementar el modelo de Minería de Datos y obtener los resultados luego de la ejecución para predecir si un alumno aprobará un curso antes de realizar su matrícula.

- OE4: Establecer el plan de continuidad para el proyecto, el cual consiste en la mejora continua del modelo y presentar propuestas en base a los resultados obtenidos a lo largo del proyecto. 


\section{Indicadores de Éxito}

\begin{tabular}{|l|l|}
\hline Indicador de Exito & $\begin{array}{l}\text { Objetivo } \\
\text { Obtenido }\end{array}$ \\
\hline $\begin{array}{l}\text { IE1: Documentación de las diferentes técnicas de entrenamiento, } \\
\text { herramientas, metodologías y algoritmos probados según la matriz } \\
\text { de información entregada y aprobada por el cliente. }\end{array}$ & OE1 \\
\hline $\begin{array}{l}\text { IE2: Documentación del modelo de minería de datos, con las } \\
\text { variables identificadas, estructurado y aprobada por el cliente, matriz } \\
\text { de información entregada aprobado por el cliente. }\end{array}$ & OE2 \\
\hline $\begin{array}{l}\text { IE3: Certificado de QS que valide los documentos de gestión del } \\
\text { proyecto. }\end{array}$ & OE3 \\
\hline $\begin{array}{l}\text { IE4: Documentación del modelo implementado utilizando data de la } \\
\text { Escuela de Ingeniería de Sistemas y Computación de la UPC } \\
\text { mostrando los resultados obtenidos aprobada por el cliente. }\end{array}$ & OE3 \\
\hline $\begin{array}{l}\text { IE5: Documentación del plan de continuidad aprobada por el cliente, } \\
\text { la cual incluye los manuales de implementación, inserción de nueva } \\
\text { data y actualización del modelo. }\end{array}$ & OE4 \\
\hline
\end{tabular}

Tabla 2 Indicadores de Éxito

Fuente: Elaboración Propia

\section{Planificación del Proyecto}

A continuación, se detalla la gestión del proyecto.

\section{Alcance}

\section{El alcance del proyecto incluirá:}

- La explicación de Data Mining y Machine Learning.

- La explicación de las diferentes técnicas, herramientas y modelos utilizados en Data Mining y Machine Learning dirigidos a datos obtenidos en universidades.

- El análisis, pruebas e implementación de las técnicas, herramientas y modelos encontrados.

- Guía de implementación del modelo generado que garantice la obtención de los resultados alcanzados a lo largo de la investigación. 
- Se desarrollará un modelo de Data Mining que puede ser aplicado en el rubro de la educación.

- La elaboración de una matriz de clasificación de los diferentes algoritmos por rubros.

- Dicho proyecto solo incluirá el análisis de toda la información generada a partir de los alumnos de la escuela de Ingeniería de Sistemas y Computación de la UPC.

- El análisis de la información de los alumnos que ingresaron a partir del ciclo 2009-I.

- Manual de Implementación del modelo y su plan de continuidad.

El alcance del proyecto no incluirá:

- No se desarrollará ninguna nueva técnica, algoritmo de Data Mining y Machine Learning.

- No se va a implementar ningún software o aplicativo que demuestre las técnicas, herramientas y modelos encontrados y/o generados a lo largo de la investigación.

\section{Plan de Gestión del Tiempo}

- A continuación, se presentan los principales hitos del proyecto, con las fechas y entregables a presentarse durante el desarrollo de este.

\begin{tabular}{|c|c|c|c|}
\hline Fase & Hito & Fecha estimada & Entregables \\
\hline Inicio & Project Charter aprobado & $02 / 09 / 2014$ & Project Charter \\
\hline \multirow{4}{*}{ Planeamiento } & $\begin{array}{l}\text { Presentación Plan de } \\
\text { Proyecto ante comité }\end{array}$ & $16 / 09 / 2014$ & $\begin{array}{l}\text { Project Charter, } \\
\text { Cronograma, } \\
\text { Plan de Trabajo }\end{array}$ \\
\hline & $\begin{array}{l}\text { Aprobación resultados de } \\
\text { algoritmo de árboles de } \\
\text { Decisión }\end{array}$ & $27 / 09 / 2014$ & $\begin{array}{l}\text { Informe de } \\
\text { Resultados del } \\
\text { Algoritmo }\end{array}$ \\
\hline & $\begin{array}{l}\text { Presentación avance Estado } \\
\text { del Arte }\end{array}$ & $02 / 10 / 2014$ & Estado del Arte \\
\hline & Presentación Marco Teórico & $02 / 10 / 2014$ & Marco Teórico \\
\hline Ejecución & $\begin{array}{l}\text { Aprobación resultados } \\
\text { algoritmo de Bayes Naive }\end{array}$ & $04 / 10 / 2014$ & $\begin{array}{l}\text { Informe de } \\
\text { Resultados del } \\
\text { Algoritmo }\end{array}$ \\
\hline
\end{tabular}




\begin{tabular}{|c|c|c|c|}
\hline Fase & Hito & $\overline{\text { Fecha estimada }}$ & Entregables \\
\hline & $\begin{array}{l}\text { KF1: Recopilar y seleccionar } \\
\text { información de la escuela }\end{array}$ & $18 / 10 / 2014$ & $\begin{array}{l}\text { Información } \\
\text { recopilada }\end{array}$ \\
\hline & $\begin{array}{l}\text { KF2: Cargar Información a } \\
\text { una base de datos SQL }\end{array}$ & $01 / 11 / 2014$ & $\begin{array}{l}\text { Información } \\
\text { Cargada }\end{array}$ \\
\hline & $\begin{array}{l}\text { KF3: Transformar los campos } \\
\text { necesarios para su análisis }\end{array}$ & $15 / 11 / 2014$ & $\begin{array}{l}\text { Campos } \\
\text { transformados }\end{array}$ \\
\hline & $\begin{array}{l}\text { KF4-5: Aplicar los algoritmos } \\
\text { e identificar patrones }\end{array}$ & $22 / 11 / 2014$ & $\begin{array}{l}\text { Patrones } \\
\text { identificados }\end{array}$ \\
\hline & Presentar Estado del Arte & $20 / 11 / 2014$ & Estado del Arte \\
\hline & Revisar la documentación & $26 / 03 / 2015$ & $\begin{array}{l}\text { Documentos } \\
\text { revisados }\end{array}$ \\
\hline & Mejorar Modelo KDD & $04 / 04 / 2015$ & $\begin{array}{l}\text { Nueva versión } \\
\text { del documento } \\
\text { KDD }\end{array}$ \\
\hline & $\begin{array}{l}\text { Investigación de } \\
\text { Implementación ETL }\end{array}$ & 04/04/2015 & $\begin{array}{l}\text { Informe de la } \\
\text { investigación }\end{array}$ \\
\hline & $\begin{array}{l}\text { Automatizar el modelo de } \\
\text { Mindata }\end{array}$ & $14 / 05 / 2015$ & $\begin{array}{l}\text { Nueva versión } \\
\text { del modelo }\end{array}$ \\
\hline & $\begin{array}{l}\text { Mejorar el modelo de } \\
\text { Mindata }\end{array}$ & $27 / 05 / 2015$ & $\begin{array}{l}\text { Documento } \\
\text { KDD }\end{array}$ \\
\hline & Implementación de ETL & $27 / 05 / 2015$ & $\begin{array}{l}\text { Proyecto en } \\
\text { Visual Studio }\end{array}$ \\
\hline & Realizar Pruebas de ETL & 06/09/2015 & $\begin{array}{l}\text { Proyecto en } \\
\text { Visual Studio }\end{array}$ \\
\hline \multirow{3}{*}{ Cierre } & $\begin{array}{l}\text { Informe Rubros de } \\
\text { Aplicación de Minería de } \\
\text { Datos }\end{array}$ & 06/09/2015 & $\begin{array}{l}\text { Documento de la } \\
\text { investigación }\end{array}$ \\
\hline & $\begin{array}{l}\text { Presentar Matriz de } \\
\text { Referencia al Cliente }\end{array}$ & $16 / 09 / 2015$ & $\begin{array}{l}\text { Matriz de } \\
\text { Referencia con } \\
\text { Algoritmos y } \\
\text { Rubros }\end{array}$ \\
\hline & Presentación del Paper & $17 / 11 / 2015$ & Paper \\
\hline
\end{tabular}




\begin{tabular}{|l|l|l|l|}
\hline Fase & \multicolumn{2}{|l|}{ Fecha estimada Entregables } \\
\hline & Presentación de la Memoria & $20 / 11 / 2015$ & Memoria \\
\cline { 2 - 4 } & Poster & $20 / 11 / 2015$ & Poster \\
\hline
\end{tabular}

Tabla 3 Hitos del proyecto

Fuente: Elaboración Propia

\section{Plan de Gestión de Recursos Humanos}

En esta sección se identifican los roles a ser considerados dentro del proyecto, las personas y las responsabilidades que deben cumplir.

La estructura organizacional del proyecto, el cual se encuentra dentro de la empresa virtual Innova TI, que pertenece a las empresas virtuales de la escuela de Ingeniería de Sistemas y computación de la UPC.

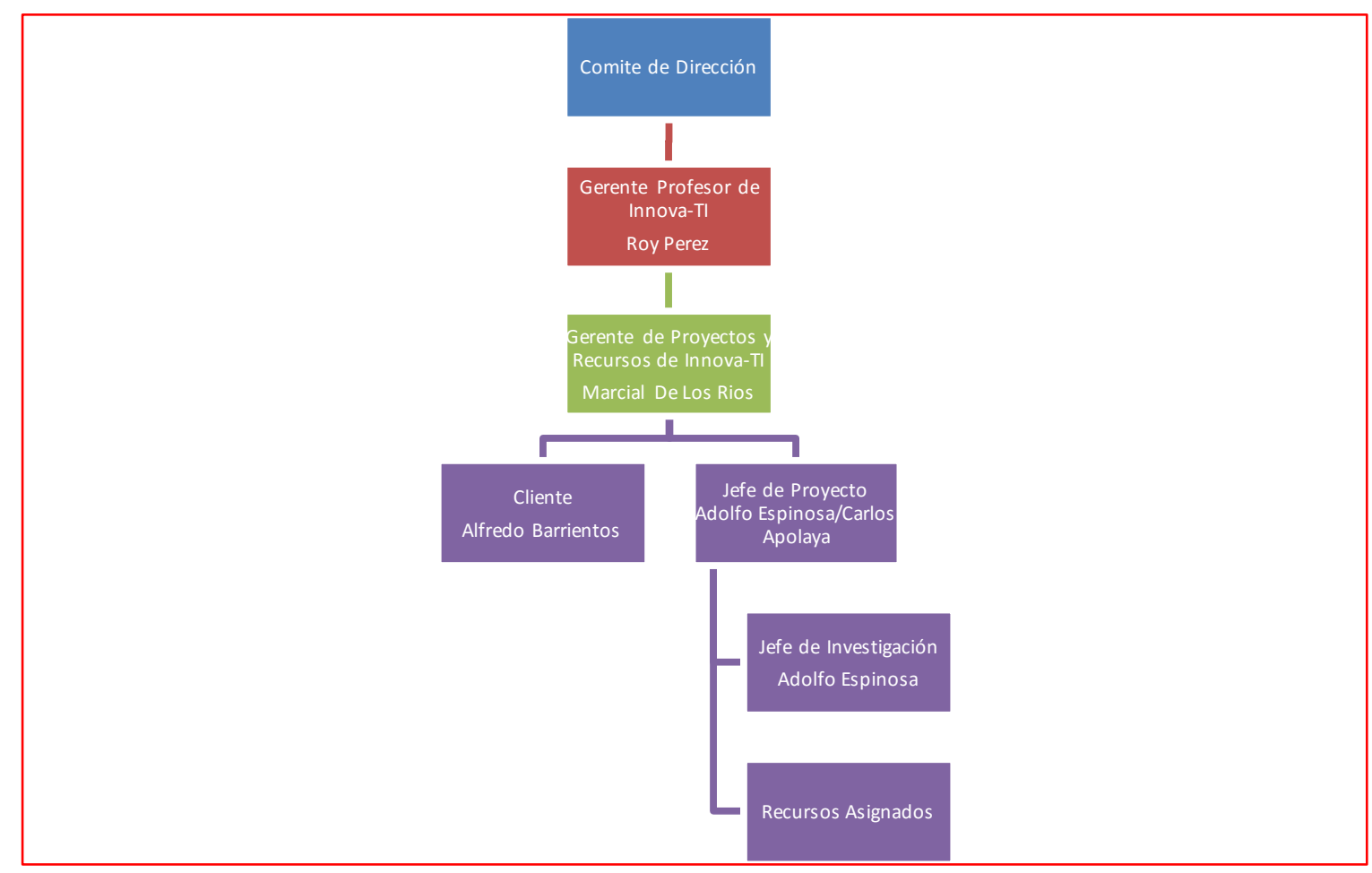

Ilustración 1: Estructura organizacional del proyecto - Ciclo 2014-II

Fuente: Elaboración propia 


\begin{tabular}{|c|c|c|}
\hline Rol & Miembro & Responsabilidades \\
\hline Roy Pérez & $\begin{array}{l}\text { Gerente profesor de la } \\
\text { empresa virtual INNOVA TI }\end{array}$ & $\begin{array}{l}\text { Gestionar juntamente con el gerente alumno } \\
\text { las tareas a realizarse por la empresa virtual } \\
\text { INNOVA TI. } \\
\text { Realizar seguimiento al proyecto } \\
\text { verificando el cumplimiento de entregables } \\
\text { planificados. }\end{array}$ \\
\hline $\begin{array}{l}\text { Alfredo } \\
\text { Barrientos }\end{array}$ & Cliente & $\begin{array}{l}\text { Evaluar y hacer seguimiento a los avances } \\
\text { del proyecto. } \\
\text { Responder consultas con respecto al } \\
\text { proyecto. } \\
\text { Aprueba los resultados del proyecto. }\end{array}$ \\
\hline $\begin{array}{ll}\text { Marcial } & \text { De } \\
\text { Los Ríos } & \end{array}$ & $\begin{array}{l}\text { Gerente de Proyectos y } \\
\text { Recursos de la empresa } \\
\text { virtual INNOVA TI }\end{array}$ & $\begin{array}{l}\text { Asegurar el cumplimiento de los objetivos } \\
\text { establecidos por cada proyecto. } \\
\text { Proveer de los recursos necesarios a los } \\
\text { proyectos bajo su gestión. }\end{array}$ \\
\hline $\begin{array}{l}\text { Recursos } \\
\text { asignados }\end{array}$ & Recursos del Proyecto & $\begin{array}{l}\text { Apoyar con la investigación del proyecto y } \\
\text { otras tareas asignadas por el equipo del } \\
\text { proyecto. }\end{array}$ \\
\hline $\begin{array}{l}\text { Carlos } \\
\text { Apolaya } \\
\text { Torres }\end{array}$ & Jefe de Proyecto & Encargado del proyecto asignado \\
\hline $\begin{array}{l}\text { Adolfo } \\
\text { Espinosa } \\
\text { Díaz }\end{array}$ & Jefe de Investigación & $\begin{array}{l}\text { Encargado de la investigación realizada en } \\
\text { el proyecto asignado }\end{array}$ \\
\hline
\end{tabular}

Tabla 4 Roles y responsabilidades

Fuente: Elaboración Propia

\begin{tabular}{|l|l|l|}
\hline Stakeholders & Necesidades & Entregables \\
\hline $\begin{array}{l}\text { Gerente profesor } \\
\text { de Innova TI }\end{array}$ & $\begin{array}{l}\text { Asegurar el cumplimiento de los } \\
\text { entregables planificado y asesorar al a } \\
\text { proyecto durante el presente ciclo. }\end{array}$ & $\begin{array}{l}\text { Project Charter } \\
\text { Cronograma } \\
\text { Actividades } \\
\text { Memoria del Proyecto }\end{array}$ \\
\hline
\end{tabular}




\begin{tabular}{|l|l|ll|}
\hline Stakeholders & Necesidades & Entregables \\
\hline $\begin{array}{l}\text { Gerente alumno } \\
\text { de innova TI }\end{array}$ & $\begin{array}{l}\text { Gestionar y verificar los avances del } \\
\text { proyecto, así como apoyar con las } \\
\text { necesidades que se presenten al equipo de } \\
\text { proyecto durante el desarrollo del proyecto. }\end{array}$ & $\begin{array}{l}\text { Project Charter } \\
\text { Actividades } \\
\text { Actas de Reunión }\end{array}$ \\
\hline $\begin{array}{l}\text { Comité } \\
\text { Dirección }\end{array}$ & $\begin{array}{l}\text { Verificar las habilidades de investigación, } \\
\text { la aplicación de conocimientos de la carrera } \\
\text { yel cumplimiento de los requisitos de la } \\
\text { investigación durante el desarrollo del } \\
\text { proyecto. }\end{array}$ & $\begin{array}{l}\text { Project Charter del } \\
\text { proyecto }\end{array}$ \\
\hline Cliente & $\begin{array}{l}\text { Obtención de la investigación sobre Data del Proyecto } \\
\text { Mining y Machine Learning }\end{array}$ & Memoria del Proyecto \\
\hline
\end{tabular}

Tabla 5 Stakeholders

Fuente: Elaboración Propia 


\section{Plan de Comunicaciones}

En esta sección se detallan las necesidades de información entre los integrantes e interesados del proyecto, así como los canales y los flujos de comunicación utilizados y lo acuerdos que se llegaron a establecer para una comunicación efectiva.

Canales de comunicación

Se considerarán los siguientes canales de comunicación con la empresa Innova TI

El medio convencional con el que se trabajará será el envío de correo a través de una cuenta Gmail personal, indicada al principio de ciclo a la gerencia.

Existe una nomenclatura para el envío de documentos a través de correo electrónico que fue acordado con la empresa en un inicio.

Si es de carácter de urgencia se puede contactar directamente a través de una llamada de celular con el gerente alumno para poder absolver la duda.

Guías para Eventos de Comunicación

Guías para reuniones - Todas las reuniones deben seguir las siguientes pautas:

Se debe establecer los puntos a tocar en la reunión

Se debe presentar todos los entregables acordados en la última reunión

Se debe acordar cuales son los nuevos entregables y las fechas para su presentación.

Se realiza un acta de reunión y todos los presentes deben firmar dicho documento.

Guías para correo electrónico

Comunicación con la gerencia de Innova TI al correo: innovati.upc.edu@gmail.com

Comunicación con el profesor gerente al correo: pcsirper@upc.edu.pe

Comunicación con el cliente: abarrientos@gmail.com

Guías para Documentación del Proyecto 
Guías para Codificación de Documentos - la codificación de los documentos del proyecto será la siguiente:

MINDATA - NOMBRE DEL DOCUMENTO V.X.X

Guías para Almacenamiento de Documentos - El almacenamiento de los documentos del proyecto deberá seguir las siguientes pautas:

Se debe almacenar todos documentos en el Drive en la carpeta correspondiente según lo asignado por el Gerente Alumno de la empresa Virtual INNOVA TI.

La ruta es: Innova TI 2015-I/Proyectos 2015-0I/Proyectos TP1/MINDATA (Carlos Apolaya y Adolfo Espinosa)/NOMBRE DE LA CARPETA A LA QUE CORRESPONDE EL DOCUMENTO

En el caso de los entregables para el cliente la ruta es la siguiente: UPC-TID-MINDATA/ NOMBRE DE LA CARPETA A LA QUE CORRESPONDE EL DOCUMENTO

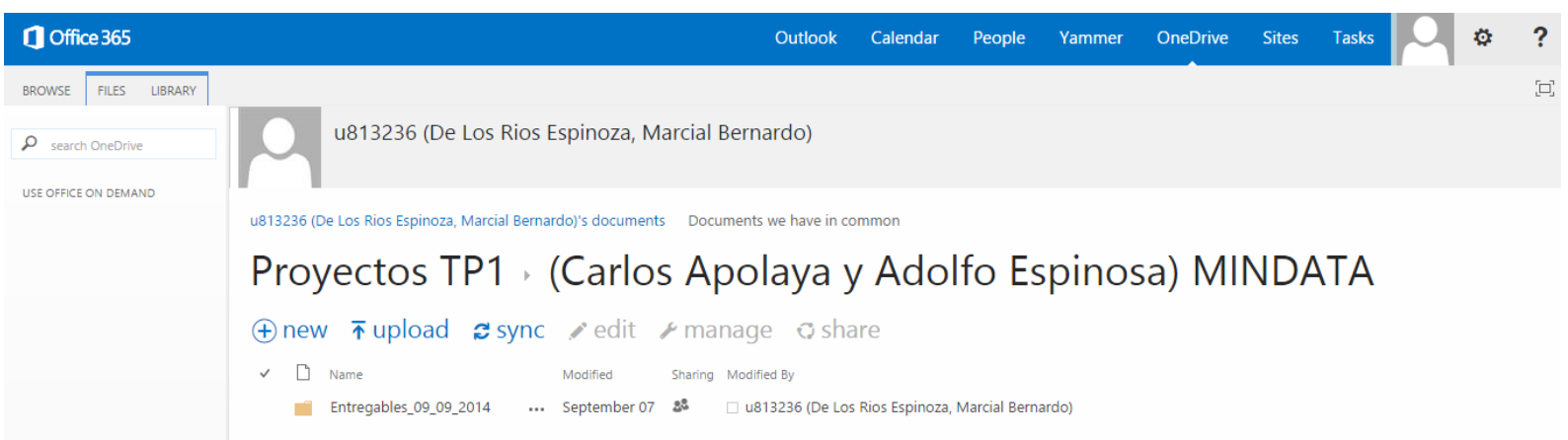

Ilustración 2: Guía de almacenamiento de documentos- MINDATA ONEDRIVE

Fuente: Elaboración propia

\subsubsection{Plan de Gestión de Riesgos}

- Escala de probabilidad: Para medir la probabilidad de ocurrencia del riesgo se usará la siguiente escala lineal:

- $\quad 0.1$ muy improbable

- 0.3 improbable 
- 0.5 moderado

- $\quad 0.7$ probable

- $\quad 0.9$ casi certeza

- Escala de impacto: Para medir el impacto de la ocurrencia del riesgo se usará la siguie nte escala lineal:

- 0.1 muy bajo

- $\quad 0.3$ bajo

- $\quad 0.5$ moderado

- $\quad 0.7$ alto

- 0.9 muy alto

Descripción de la metodología de gestión de riesgo a ser usada

\begin{tabular}{|l|l|l|l|l|l|}
\hline$\#$ & Riesgo & $\begin{array}{l}\text { Probabilida } \\
\text { d }\end{array}$ & Impacto & $\begin{array}{l}\text { Probabilida } \\
\text { d x Impacto }\end{array}$ & Estrategia de mitigación \\
\hline 1 & $\begin{array}{l}\text { Escasa } \\
\text { información } \\
\text { del tema de } \\
\text { investigació } \\
\text { n }\end{array}$ & Moderado & Alto & 0.35 & $\begin{array}{l}\text { Búsqueda de fuentes } \\
\text { confiables que aporten al } \\
\text { desarrollo de la } \\
\text { investigación. }\end{array}$ \\
\hline 2 & $\begin{array}{l}\text { Disponibilid } \\
\text { ad del } \\
\text { cliente }\end{array}$ & Amprobable & Alto & 0.21 & $\begin{array}{l}\text { Coordinar fechas de } \\
\text { reunión durante el ciclo } \\
\text { para evaluar los avances. }\end{array}$ \\
\hline 3 & $\begin{array}{l}\text { Mala } \\
\text { traducción } \\
\text { de los } \\
\text { términos al } \\
\text { castellano }\end{array}$ & Improbable & Bajo & 0.09 & $\begin{array}{l}\text { Buscar un recurso que } \\
\text { tenga el dominio del } \\
\text { idioma para asegurar la } \\
\text { correcta traducción y el } \\
\text { uso de los términos en } \\
\text { castellano. }\end{array}$ \\
\hline 4 & $\begin{array}{l}\text { Demora en } \\
\text { la Improbable }\end{array}$ & Alto & 0.21 & $\begin{array}{l}\text { Emplear horas o días que } \\
\text { no están programadas en el }\end{array}$ \\
\hline
\end{tabular}




\begin{tabular}{|c|c|c|c|c|c|}
\hline \# & Riesgo & $\begin{array}{l}\text { Probabilida } \\
\text { d }\end{array}$ & Impacto & $\begin{array}{l}\text { Probabilida } \\
\text { d x Impacto }\end{array}$ & Estrategia de mitigación \\
\hline & $\begin{array}{l}\text { realización } \\
\text { de le los } \\
\text { entregables }\end{array}$ & & & & $\begin{array}{ll}\text { cronograma } & \text { de } \\
\text { actividades. } & \end{array}$ \\
\hline 5 & $\begin{array}{l}\text { Recurso } \\
\text { asignado no } \\
\text { cumpla con } \\
\text { las tareas } \\
\text { encomenda } \\
\text { das por el } \\
\text { equipo de } \\
\text { proyecto }\end{array}$ & Improbable & Moderado & 0.15 & $\begin{array}{l}\text { Asignar tareas que cubra el } \\
\text { tiempo que debe cumplir } \\
\text { el recurso como apoyo } \\
\text { para el proyecto. } \\
\text { Si no cumple con las tareas } \\
\text { notificar a la gerencia de la } \\
\text { empresa y de ser necesario } \\
\text { reasignar otro recurso. }\end{array}$ \\
\hline 6 & $\begin{array}{l}\text { Cambio del } \\
\text { cliente } \\
\text { actual del } \\
\text { proyecto }\end{array}$ & Improbable & Alto & 0.21 & 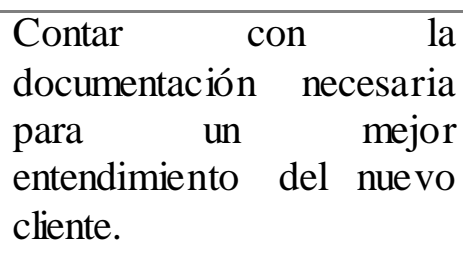 \\
\hline 7 & $\begin{array}{ll}\text { Cambio } & \text { del } \\
\text { alcance } & \text { del } \\
\text { proyecto } & \end{array}$ & Moderado & Alto & 0.35 & $\begin{array}{l}\text { Reorganización } \\
\text { cronograma } \\
\text { actividades. }\end{array}$ \\
\hline 8 & $\begin{array}{l}\text { No contar } \\
\text { con las } \\
\text { herramienta } \\
\text { s requeridas }\end{array}$ & Moderado & Alto & 0.35 & $\begin{array}{l}\text { Solicitar el software a la } \\
\text { directora de la carrera en } \\
\text { caso no se pueda obtener } \\
\text { por cualquier otro medio. }\end{array}$ \\
\hline 9 & $\begin{array}{ll}\text { Cambio } & \text { de } \\
\text { jefes } & \text { de } \\
\text { proyecto } & \end{array}$ & Improbable & Alto & 0.21 & $\begin{array}{l}\text { Debido a un accidente o } \\
\text { problemas de fuerza } \\
\text { mayor uno o ambos jefes } \\
\text { de proyecto actuales } \\
\text { podrían ser suplantados } \\
\text { por lo que se tendría que } \\
\text { tener todo el proyecto bien } \\
\text { documentado para el } \\
\text { entendimiento de los } \\
\text { futuros JP. }\end{array}$ \\
\hline
\end{tabular}

Tabla 6 Riesgos

Fuente: Elaboración Propia 


\section{CAPÍTULO 2: Marco Teórico}

El presente capítulo define los conceptos básicos y relacionados al tema de estudio de la investigación. Se especifica la definición de los componentes principales del proyecto, minería de datos, entre otros términos necesarios para la comprensión del proyecto. 


\section{Data Mining}

Según Gordon S.Linoff, se podría definir Data Mining como un proceso de negocio para analizar gran cantidad de data para descubrir patrones y reglas significativas. Es el proceso de detectar la información procesable de grandes conjuntos de datos. Utiliza el análisis matemático y estadístico para deducir los patrones y tendencias que existen en los datos. Normalmente, estos patrones no se pueden detectar mediante la exploración tradicional de los datos ya que las relaciones son demasiado complejas o porque existe demasiado información que analizar. Estos patrones y tendencias se pueden recopilar y definir como un modelo de minería de datos 1

\section{Proceso de Negocio}

Se considera a la minería de datos un proceso de negocio que interactúa con otros procesos del negocio. Este inicia con la data, luego mediante un análisis informa o inspira acciones que a su vez generan datos que generan más minería de datos. La estrategia de negocio consiste en recolectar data, analizarla para obtener beneficios a largo plazo y actuar en base a los resultados obtenidos.

Ante la pregunta ¿Qué es gran cantidad de data?, algunos estudiantes responderán "las transacciones de 10 millones de clientes", "terabytes de datos". Incluso Microsoft ha permitido más de un millón de filas en las hojas de cálculo en Excel desde el 2007.

En los años de 1960 y 1970, la data era escasa ya que los dataset contenían unos cientos de registros. En la actualidad, los dataset son un testimonio de la fuerza de las técnicas desarrolladas en aquellos días, que todavía trabajan en los datos que ya no caben en las hojas de cálculo.

Debido a que la potencia de cálculo es de fácil acceso, una gran cantidad de datos no es una desventaja; es una ventaja, ya que muchas de las técnicas existentes trabajan mejor con data de gran tamaño. La minería de datos permite a las computadoras hacer lo que mejor hacen, indagar sobre montones y montones de datos. Esto a su vez permite a las personas hacer lo que mejor hacen, que es analizar los problemas y entender los resultados.

\footnotetext{
${ }^{1}$ Cfr. Micros oft 2014
} 


\section{Patrones y Reglas}

La minería de datos puede generar miles e incluso millones de patrones y reglas. Para ello uno debe primero enfocar un objetivo y/o plantear una hipótesis. Después, se debe verificar si los patrones hallados son fáciles de entender por los humanos, ya que no todos serán de gran utilidad. Luego, verificar si dichos patrones ayudan a validar la hipótesis planteada al inicio del proyecto. $^{2}$

\section{Ciclo del Data Mining}

1. La identificación de oportunidades de negocio

2. Minería de datos para transformar los datos en información procesable

3. Actuando sobre la información

4. Medición de los resultados

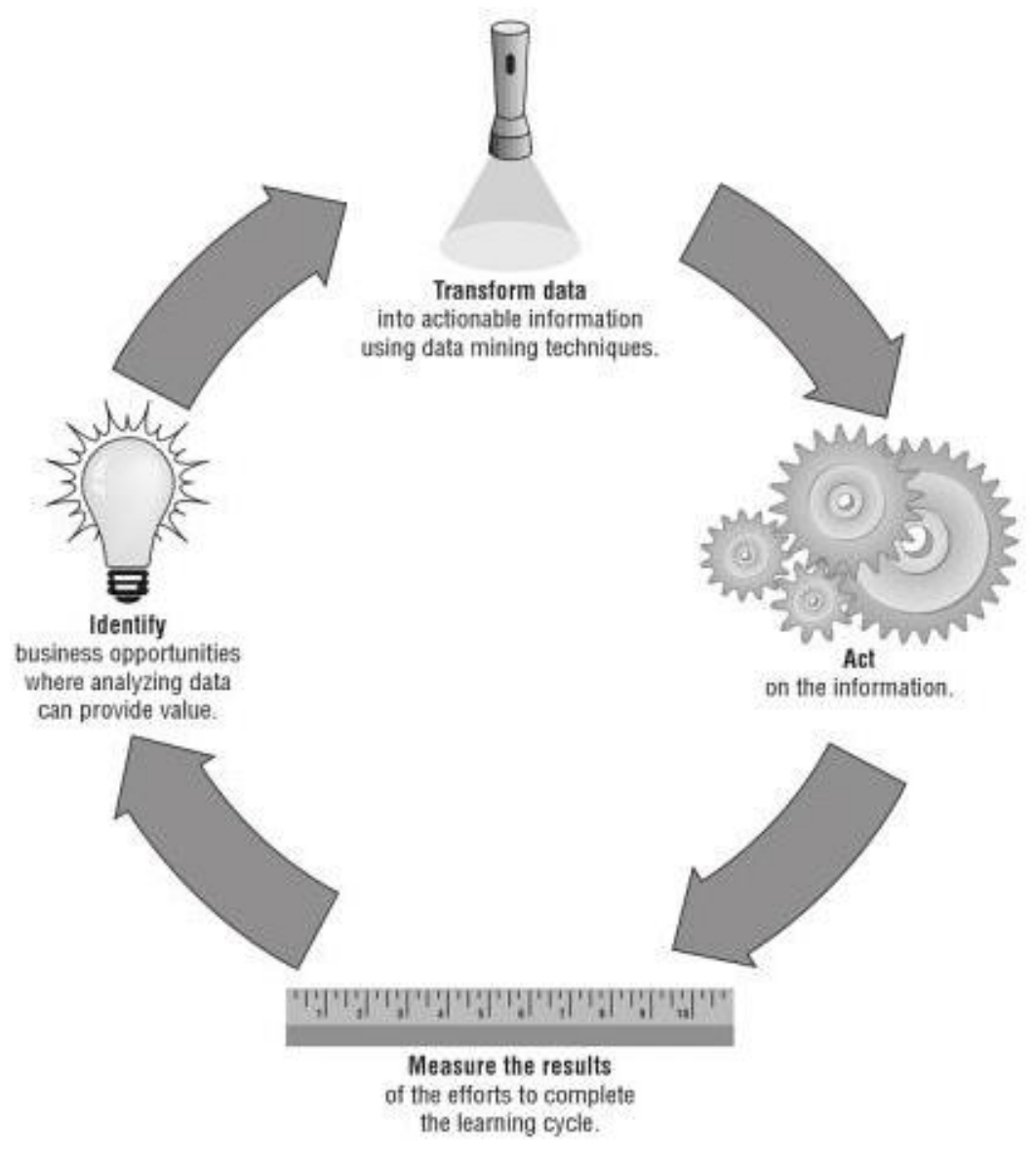

${ }^{2}$ Cfr. Han 2012 
Ilustración 3: Ciclo de Vida de Data Mining

Fuente: LINOFF 2011: 26

\section{Estilos de Data Mining}

El proceso de Data Mining puede fallar en muchas formas, esto se debe a distintos factores como:

- La data usada no es representativa

- Los patrones elegidos no aportaban al negocio

- La mezcla de información que contiene periodos que debían estar separados.

Es por eso por lo que se tiene que definir correctamente los componentes del Data Mining. Para que el proceso de Data Mining sea el adecuado, se debe tener en cuenta:

Hay tres estilos que pueden ser usados por separado o juntos si en caso se requiera para cumplir ciertos objetivos:

- Exploratorio: Da perspectivas y responde preguntas en lugar de producir modelos. Es frecuente que se den hipótesis que puedan o no ser demostrada con el uso de datos.

- Minería de datos dirigido: Se utiliza cuando los datos históricos contienen ejemplos de lo que se está siendo buscado, es decir tienen un objetivo definido.

- Minería de datos no dirigido: No tiene un objetivo definido, es como coger un conjunto de data y "tirarla" a la computadora para ver donde cae, es decir que sin un objetivo definido no se puede saber si el resultado es el correcto o no.

El proceso de minería de datos se inicia con un objetivo de negocio. El proceso consiste en traducir el objetivo de negocio en una o más tareas de minería de datos. Después que las tareas han sido definidas, naturaleza, tipos de variables, la estructura en que se obtendrán los resultados y la compensación entre el "accuracy model" y el "explicability model" influye en la elección de la técnica de minería de datos. 
Table 3-1: What Techniques for Which Tasks?

\begin{tabular}{lll}
\hline TASK & BEST FIT & ALSO CONSIDER \\
$\begin{array}{l}\text { Classification } \\
\text { and prediction }\end{array}$ & $\begin{array}{l}\text { Decision trees, logis- } \\
\text { tic regression, neural } \\
\text { networks }\end{array}$ & $\begin{array}{l}\text { Similarity models, table look-up } \\
\text { models, nearest neighbor models, } \\
\text { naïve Bayesian models }\end{array}$ \\
\hline Estimation & $\begin{array}{l}\text { Linear regression, neural } \\
\text { networks }\end{array}$ & $\begin{array}{l}\text { Regression trees, nearest neighbor } \\
\text { models }\end{array}$ \\
\hline Binary response & $\begin{array}{l}\text { Logistic regression, deci- } \\
\text { sion trees }\end{array}$ & $\begin{array}{l}\text { Similarity models, table look-up } \\
\text { models, nearest neighbor models, } \\
\text { naïve Bayesian models }\end{array}$ \\
\hline $\begin{array}{l}\text { Finding clusters } \\
\text { and patterns }\end{array}$ & $\begin{array}{l}\text { Any of the clustering } \\
\text { algorithms }\end{array}$ & Association rules \\
\hline
\end{tabular}

Ilustración 4: tareas por técnica

Fuente: LINOFF 2011: 98

- Varianza: Es la medida de la dispersión de valores de datos. Una baja varianza significa que el valor está cerca del promedio mientras que una alta dispersión indica lo contrario

- Desviación Estándar: Es la raíz cuadrada de la varianza y es la más usada como medida de dispersión ya que esta expresada en las mismas unidades que los valores en términos de unidades cuadradas.

- Intervalos de Confianza: Es una medida de una sola cosa, la dispersión de una muestra estimada con respecto a la población estimada.

\section{Machine Learning}

Machine Learning, también conocido como aprendizaje automático en español, tiene muchas definiciones. Por un lardo, Tom Mitchell lo define como un programa de computadora que cuando realiza determinada tarea con cierto rendimiento, entonces gana cierta experiencia que le permite aumentar el rendimiento con el que realiza dicha tarea ${ }^{3}$. Por otro lado, Arthur Samuel indica que es el campo de estudio en las computadoras tienen la habilidad de aprender sin haber sido explícitamente programada ${ }^{4}$. Machine Learning se clasifica dentro del ámbito de la

\footnotetext{
${ }^{3}$ Cfr. Brange 2013

${ }^{4}$ Cfr. Brange 2013
} 
Inteligencia Artificial que forma parte de una de las ramas que conforman las ciencias de la computación $n^{5}$.

Hoy en día Machine Learning permite a cualquier persona trabajar sus datos y de esta manera alcanzar una mayor ventaja competitiva. Anteriormente, esto solo estaba al alcance de las grandes empresas y corporaciones ${ }^{6}$.

\section{Tipos de Algoritmos}

Los algoritmos de Machine Learning se clasifican en función del resultado deseado del algoritmo. Entre los tipos más comunes se encuentran los siguientes ${ }^{7}$ :

\section{Aprendizaje supervisado}

Este algoritmo es el que toma un conjunto conocido de datos de entrada y conoce la respuesta a los datos con lo que trata de construir un modelo de predicción que permita realizar predicciones razonables como respuesta a nuevos datos. Este flujo se puede ver de manera más clara en la siguiente imagen ${ }^{8}$.

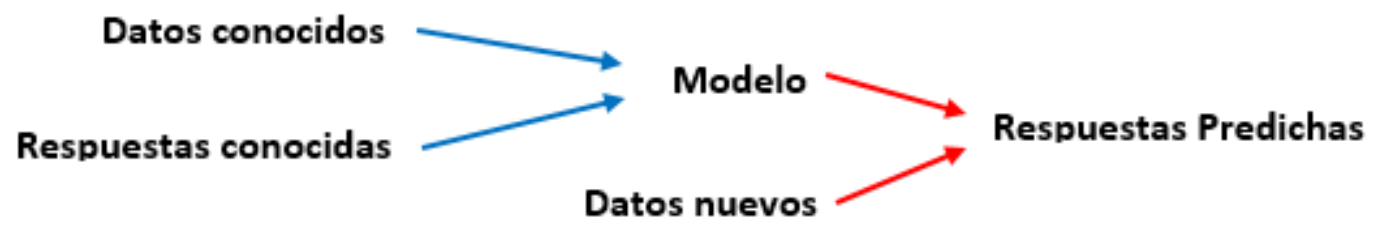

Ilustración 5: aprendizaje supervisado 1

Fuente: Elaboración propia

Este tipo de algoritmo supervisado se divide a su vez en dos categorías. Por un lado, se encuentra el aprendizaje supervisado de tipo regresión porque intenta predecir resultado dentro de una salida continua la cual se refiere a un valor numérico real ${ }^{9}$. Por otro lado, se encuentra

\footnotetext{
${ }^{5}$ Cfr. Brange 2013

${ }^{6}$ Cfr. González 2014

${ }^{7}$ Cfr. Oladipupo 2014: 19

${ }^{8}$ Cfr. MathWorks 2014

${ }^{9}$ Cfr. Brange 2013
} 
al aprendizaje supervisado de tipo clasificación que se encarga de predecir resultados discretos que forman un conjunto de resultados finito como podrían ser categorías o etiquetas ${ }^{10}$.

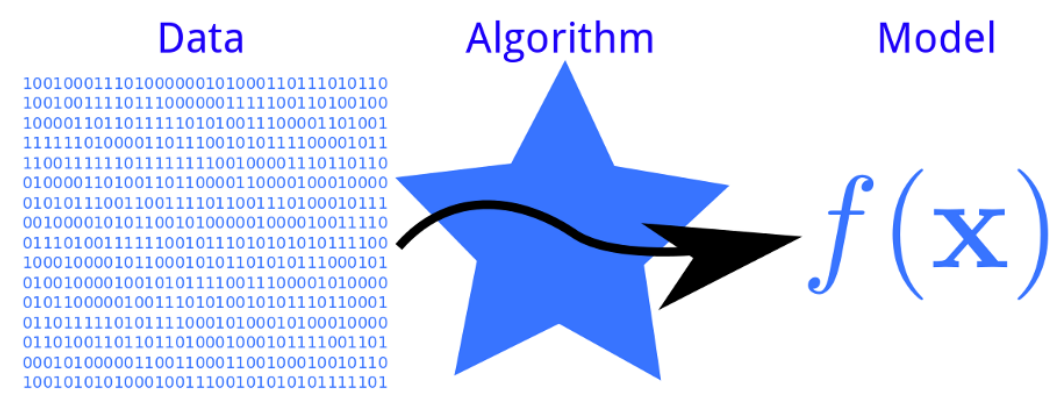

Ilustración 6: aprendizaje supervisado 2

Fuente: GitHub 2013

\section{Aprendizaje no supervisado}

Este algoritmo trabaja con situaciones en las cuales no se conoce o se sabe muy poco respecto a los resultados que se esperan predecir. Sin embargo, se puede encontrar estructuras gracias al agrupamiento de datos que se basa entre las relaciones que se pueden identificar de las variables de los datos de entradas, pero esta no es la única forma de aprendizaje no supervisado $^{11}$.

Entre los principales ejemplos de aprendizaje no supervisado se encuentran el clustering y la asociación ${ }^{12}$. Por un lado, el clustering permite, dada una colección de datos, encontrar una forma de agrupación según las variables que se identifiquen. Por otro lado, la asociación permite buscar la relación entre un conjunto de datos para poder hacer una predicción.

\section{Aprendizaje semi-supervisado}

Este algoritmo representa la combinación de los dos tipos de algoritmos anteriores para crear una función apropiada.

\footnotetext{
${ }^{10}$ Cfr. Brange 2013

${ }^{11}$ Cfr. Brange 2013

${ }^{12}$ Cfr. Brange 2013
} 


\section{Aprendizaje por refuerzo}

Este algoritmo que aprende a actuar dado los factores del exterior y aquellos primeros hechos proporcionados. En otras palabras, cada acción genera un impacto en el entorno, y el medio ambiente proporciona información que guía el aprendizaje del algoritmo.

\section{Transducción}

Este algoritmo es similar al del aprendizaje supervisado, pero no construye de forma explícita una función. Sin embargo, trata de predecir nuevos resultados a base de entradas de entrenamiento, salidas de entrenamiento y nuevas entradas.

\section{Aprendiendo a aprender}

Este algoritmo utiliza los conocimientos que ya ha aprendido anteriormente para afrontar problemas similares que se presenten en el futuro de la misma manera que lo hizo antes.

\section{Técnicas de Entrenamiento}

En este punto se presentará las técnicas de entrenamiento de Machine Learning, tales como la técnica basadas en árboles de decisión, regresión lineal, redes bayesianas, support vector machine $^{13}$ y vecino más cercado. Se entrará a más detalle

\section{Método basado en árbol de decisión}

Este método tiene el enfoque fundamental de aprendizaje en dividir de forma recursiva los datos de entrenamiento en "cubetas" con miembros homogéneos según criterios de divis ión discriminativa. Este criterio se basa en la etiqueta de salida, ya que si es un valor número será la varianza de la "cubeta", pero si se trata de una categoría, la medición será la entropía de la "cubeta"14.

Las ventajas del árbol es que es muy flexible en lo que respecta a los tipos de datos de entrada y de salida, ya que pueden ser valores categóricos, binarios y numéricos. También, el nivel de nodos de decisión indica el grado de influencia de diferentes variables de entrada ${ }^{15}$.

\footnotetext{
${ }^{13}$ Cfr. Ho 2012

${ }^{14}$ Cfr. Ho 2012

${ }^{15}$ Cfr. Ho 2012
} 


\section{Método basado en regresión lineal}

Este método se basa en que la variable de salida mayormente es un valor numérico, se puede expresar como una combinación lineal (suma ponderada) de un conjunto de variables de entrada, que deben ser también numéricas ${ }^{16}$. Esta se puede ver de manera más clara en la siguiente expresión:

$y=X_{1} \times W_{1}+X_{2} \times W_{2}+X_{3} \times W_{3}+\ldots$

Ilustración 7: regresión lineal

Fuente: elaboración propia

Debido a esto, lo que se busca es aprender los pesos (Variables "W") en la fase de entrenamiento reduciendo al mínimo la función de error perdido. Entre las ventajas de este modelo se encuentra el alto rendimiento en las fases de puntuación y aprendizaje. Por otro lado, la desventaja de este modelo es la suposición lineal de las características de entrada que generalmente son falsas ${ }^{17}$.

\section{Red Bayesiana}

Este método se trata básicamente de un gráfico de dependencias donde cada nodo representa una variable binaria y cada direccional representa la relación de dependencia ${ }^{18}$. La principal fortaleza de la red bayesiana es que es escalable y tiene un aprendizaje incremental debido a que se actualiza la tabla de distribución de probabilidades cada vez que se encuentra una nueva variable $^{19}$.

\section{Vecino más cercano}

Esta técnica emplea una función de la distancia que se utiliza para encontrar al vecino más cercano mediante el cual se les asigna un peso. La ventaja de esta técnica es su sencillez, ya que ningún modelo necesita ser entrenado y su aprendizaje incremental es automático cuando se ingresan nuevos datos ${ }^{20}$.

\footnotetext{
${ }^{16}$ Cfr. Ho 2012

${ }^{17}$ Cfr. Ho 2012

${ }^{18}$ Cfr. Ho 2012

${ }^{19}$ Cfr. Ho 2012

${ }^{20}$ Cfr. Ho 2012
} 
En los últimos años, Machine Learning se está volviendo uno de los cursos populares en las universidades del mundo y tiene una gran presencia en todo el mundo. Existen varios casos de éxito de empresas que aplicaron el Machine Learning siendo una de estas las siguientes ${ }^{21}$ :

Amazon ha encontrado la forma de automatizar el control de acceso que tienen sus empleados a ciertos recursos. Esto lo logro convocando a un concurso de Machine Learning empleando la herramienta Kaggle para poder encontrar la forma de automatizar el otorgamiento y revocación de acceso de los empleados según los roles de estos.

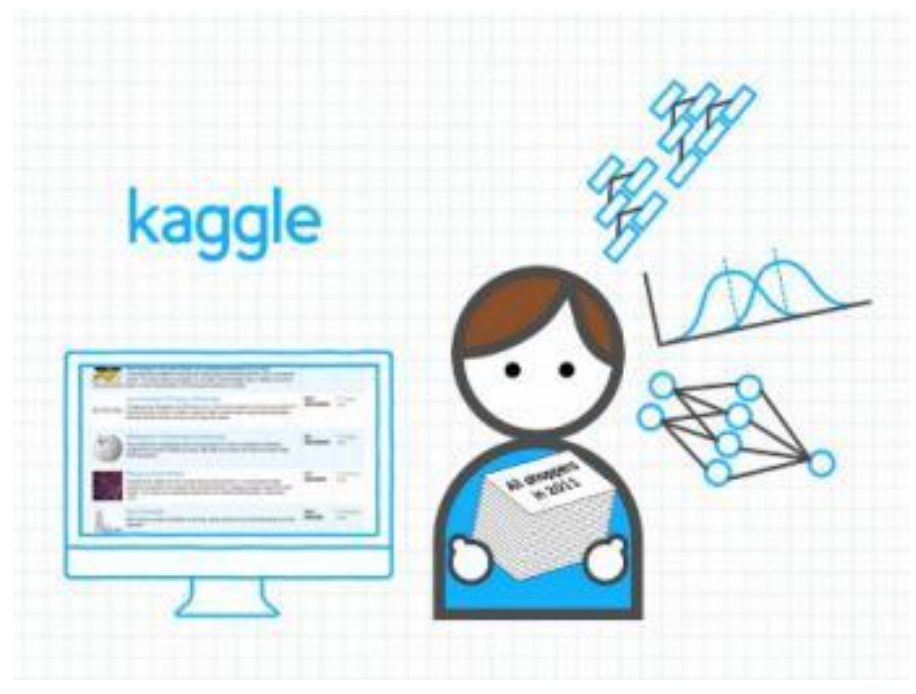

Ilustración 8: kaggle

Fuente: RFI english 2012

En el aspecto de la protección animal, la Universidad Estatal de Oregon ha construido un software que mediante grabaciones de audio de aves y dependiendo de la zona o lugar donde fue tomado dicho audio, puede identificar que especie de ave se encuentra en la zona empleando herramientas como MathLab y Python.

\section{คి python}

Ilustración 9: python

\footnotetext{
${ }^{21}$ Cfr. Hamilton 2014
} 
En el ámbito de la medicina, Healint lanzó una aplicación llamada JustShakelt que permite al usuario enviar una alerta a los contactos simplemente agitándolo el teléfono con una mano. Este programa emplea un algoritmo de Machine Learning que distingue cuando un usuario agita su celular en emergencias reales de las que comúnmente ocurren todos los días.

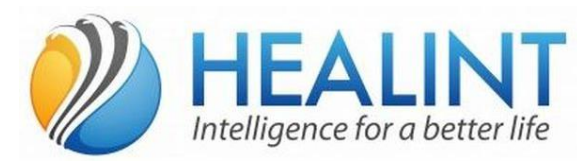

Ilustración 10: Healint

Fuente: Asiahack 2014

\section{Técnicas de Validación}

Existen varias técnicas o modelos de validación para medir que tan bien una computadora aprende ya sea a clasificar, agrupar, etc. Entre las principales técnicas se encuentra crossvalidation, complexity criteria ${ }^{22} y$ generalization error ${ }^{23}$. A continuación, se presentará h técnica más utilizada y difundida:

\section{Cross-Validation}

Este es un modelo de validación usado para analizar los resultados de una evaluación estadística. Esto se realiza a partir de la división aleatoria de un conjunto de datos destinando una parte, que generalmente es la mayor, como conjunto de aprendizaje para entrenar a la computadora y la otra parte para el conjunto de validación (10-20\%). Esto es necesario para la correcta validación del aprendizaje ganado ${ }^{24}$.

Sin embargo, existen casos en los que se utiliza una sola muestra para la validación, en este caso el método recibe el nombre de leaver-one-out crossvalidation. Este tipo de evaluación del rendimiento carece de eficiencia computacional debido a su estructura repetida, pero posee menor varianza en la estimación ${ }^{25}$. Entre otras características del Cross-validation se encuentra

\footnotetext{
${ }^{22}$ Cfr. Springer 2014: 28

${ }^{23}$ Cfr. Springer 2014: 21

${ }^{24}$ Cfr. Springer 2014: 26

${ }^{25}$ Cfr. Springer 2014: 26
} 
la diferencia entre: los datos que se emplean en el conjunto de aprendizaje con respecto al conjunto de evaluación, los cuales permiten seleccionar de manera más acertada el mejor modelo estimado 26 .

\section{Collaborative Filtering}

Con el avance rápido de la tecnología en estos días, el internet se ha vuelto una herramienta de búsqueda que permite tener toda la información que necesitas a la mano en tiempo real. Sin embargo, existe tanta información y diversas fuentes que a veces resultado difícil encontrar la información que realmente queremos. Es debido a este problema que aparecen los sistemas de filtros. Esta herramienta te permite separar la información que realmente te interesa de la que simplemente no necesitas. Existen diversas formas de realizar un filtrado de información, pero en este caso se investigará más a fondo la técnica del Collaborative Filtering.

\section{Conceptos Previos}

Para poder entender mejor la idea de lo que es un Collaborative Filtering, es necesario explicar lo que es un sistema de recomendaciones. Un sistema de recomendaciones es, como su mismo nombre lo indica, un sistema que utiliza una técnica de filtrado para poder recomendar o sugerir a un usuario alguna cosa $u$ objeto que podría gustarle ${ }^{27}$ mediante el análisis de la información. Este análisis se realiza sobre los gustos de una persona y otros grupos de usuarios con las mismas características para poder predecir qué cosa podría gustarle también a otro usuario con igual similitud de características ${ }^{28}$. Los sistemas de recomendación se pueden basar en 3 tipos de análisis ${ }^{29}$ :

\section{Análisis de los ítems:}

Este primer tipo de análisis se encarga de analizar un conjunto de datos (ítems consumidos) con la finalidad de identificar sus características. Una vez realizado esto se identifican sus similitudes con la finalidad de realizar recomendaciones en base a información de otros productos consumidos por los clientes que compraron el ítem analizado.

$\underline{\text { Análisis de los usuarios: }}$

\footnotetext{
${ }^{26}$ Cfr. Springer 2014: 26

${ }^{27}$ Cfr. GIMENO 2010: 3

${ }^{28}$ Cfr. GALÁN 2007: 1

${ }^{29}$ Cfr. GIMENO 2010: 4-6
} 
Este segundo tipo de análisis se encarga de identificar un usuario con la finalidad de recomendarle productos consumidos por otro grupo de usuarios con los que comparta gustos, preferencias o intereses.

Análisis de las relaciones entre ítems y usuarios:

Este tercer tipo de análisis hace una mezcla entre los dos anteriores teniendo en cuenta tanto la similitud entre las características de los usuarios como las características de los productos que escogen.

\section{Definición y Características}

Collaborative Filtering, también conocido como filtro colaborativo en español, es una de las muchas técnicas que emplean los Sistemas de Recomendaciones para poder encontrar usuarios que tengan gustos similares a otros y poder sugerirles cosas que aún no conocen pero que a otros con sus mismas características les gusta ${ }^{30}$. Dicho en otras palabras, permite predecir la utilidad que tendría determinado objeto para un usuario particular según sus gustos compartidos con otras personas con quienes comparte también los mismos intereses ${ }^{31}$.

Sin embargo, para poder realizar esta sugerencia se necesita realizar un procesamiento de la información brindada por todos los usuarios (Calificaciones, opiniones y evaluaciones que hacen sobre los objetos). Muchos de estos procedimientos se hacen mediante el uso de algoritmos de minería de datos para encontrar el valor de la información recopilada ${ }^{32}$.

El flujo del proceso de filtrado colaborativo se suele representar de la siguiente manera ${ }^{33}$ :

Se parte de la idea de que los gustos de un grupo de usuarios en el pasado serán los mismos más adelante. Entonces, se procede a analizar los gustos de una población para poder recomendar productos más adelante.

Se les da la opción a los usuarios a calificar y dar puntuación de los productos que compran para poder almacenar toda esa información dentro de una base de datos.

\footnotetext{
${ }^{30}$ Cfr. GALÁN 2007: 1

${ }^{31}$ Cfr. HUECAS 2010: 25

${ }^{32}$ Cfr. GALÁN 2007: 1

${ }^{33}$ Cfr. GÓMEZ 2012: 19
} 
Se procede a analizar y procesar toda esa información mediante algoritmos de minería de datos para obtener una predicción de los objetivos o productos que podría gustarle o no a un usuario.

Usos y Aplicaciones

El Collaborative Filtering es uno de los temas que se está viendo mucho actualmente en diversas publicaciones y congresos durante los últimos años. También, está presente en diferentes ámbitos como el de las redes sociales y esto se ha visto propiciado por el gran avance logrado con la Web 2.0 $0^{34}$. Entre los principales usos y aplicaciones del filtro colaborativo se encuentran los siguientes ${ }^{35}$ :

\section{Tiendas On-line:}

La idea básica de usar el filtro colaborativo en las páginas de tiendas online es sugerir otros productos a partir de la búsqueda de un producto específico teniendo en cuenta los productos que también compraron los otros usuarios además del que se buscó. Este filtro está presente en varias páginas siendo la más popular Amazon.

\section{Noticias:}

A partir de las noticias que consulta un usuario se va generando su perfil y se puede predecir qué tipo de noticias le gusta o lee más.

Búsqueda de música, libros, películas:

De igual forma que las anteriores, cuando un usuario reproduce una canción, compra un libro o una película, esta información se almacena dentro de una base de datos de la cual podrán realizar sugerencias sobre otros libros, canciones o películas que podrían interesarle. Sin embargo, dicha información no solo podría resultar provechoso para los mismos usuarios, sino también para las empresas discográficas, autores y directores de cine para poder saber cuáles son las nuevas tendencias en cada uno de sus rubros.

\section{Búsqueda de personas:}

\footnotetext{
${ }^{34}$ Cfr. GALÁN 2007: 2

${ }^{35}$ Cfr. GALÁN 2007: 2
} 
Dentro de las comunidades virtuales se pueden sugerir amigos a partir de los gustos, hobbies, centro de estudios, amigos en común.

\section{Cuadro comparativo entre Machine Learning y Data Mining}

Entre los muchos términos que manejan se tiene que Data Mining está enfocado en predecir patrones basados en las propiedades conocidas extraídas de los datos de entrenamiento, mientras que Machine Learning se centra en el descubrimiento de estas propiedades para poder clasificar los datos en diferentes grupos en función a sus atributos.

Un ejemplo claro sería que el Data Mining, pueda decir en base al rostro que aparece en la imagen el nombre de la persona que aparece en ella, ya que posee parámetros o patrones que han sido definidos previamente.

Mientras que el Machine Learning se encarga de definir estos patrones y parámetros para su posterior análisis.

A continuación, se mostrará un cuadro de como Machine Learning y Data Mining definen estos términos.

\begin{tabular}{|l|l|l|}
\hline Parámetros & Data Mining & Machine Learning \\
\hline Definición & $\begin{array}{l}\text { La minería de datos es un proceso } \\
\text { para extraer información de una } \\
\text { data set y transformarla en una } \\
\text { estructura entendible para más } \\
\text { usos. }\end{array}$ & $\begin{array}{l}\text { Es una técnica que se refiere al } \\
\text { estudio y construcción de sistemas } \\
\text { que pueden aprender a partir de } \\
\text { datos. }\end{array}$ \\
\hline Enfoque & $\begin{array}{l}\text { Se enfoca en el descubrimiento de } \\
\text { propiedades desconocidas de los } \\
\text { datos. }\end{array}$ & $\begin{array}{l}\text { Se enfoca en la predicción basada } \\
\text { en propiedades conocidas } \\
\text { aprendidas a partir de datos de } \\
\text { entrenamiento. }\end{array}$ \\
\hline $\begin{array}{l}\text { Tamaño de base } \\
\text { de datos }\end{array}$ & $\begin{array}{l}\text { Es un análisis automático o semi- } \\
\text { automático que se realiza en } \\
\text { grandes cantidades de datos. }\end{array}$ & $\begin{array}{l}\text { Generalmente realizada en } \\
\text { pequeñas bases de datos para } \\
\text { incrementar la exactitud o } \\
\text { precisión. }\end{array}$ \\
\hline Tipos & $\begin{array}{l}\text { Reglas de Asociación } \\
\text { Clasificación }\end{array}$ & $\begin{array}{l}\text { Supervisado } \\
\text { No supervisado }\end{array}$ \\
\hline
\end{tabular}




\begin{tabular}{|c|c|c|}
\hline Parámetros & Data Mining & Machine Leaming \\
\hline & $\begin{array}{l}\text { Clustering } \\
\text { Patrones de secuencia } \\
\text { Similitud de secuencia }\end{array}$ & Refuerzo \\
\hline Relación & $\begin{array}{l}\text { Minería de datos usa varios } \\
\text { métodos de aprendizaje por } \\
\text { computadora, pero ligerame nte } \\
\text { para distintos objetivos. }\end{array}$ & $\begin{array}{l}\text { Aprendizaje por computadora } \\
\text { también usa técnicas de minería de } \\
\text { datos como "aprendizaje no } \\
\text { supervisado" o como un "paso de } \\
\text { preprocesamiento" para mejora de } \\
\text { la precisión del aprendiz. }\end{array}$ \\
\hline Aplicaciones & $\begin{array}{l}\text { Previsión } \\
\text { Objetos clasificatorios } \\
\text { Asociando objetos similares } \\
\text { Clustering en grupos } \\
\text { Tomas de secuencias }\end{array}$ & $\begin{array}{l}\text { Automatización de control de } \\
\text { acceso de los empleados. } \\
\text { Protección a los animales } \\
\text { Identificando fallas del corazón. } \\
\text { Predecir tiempos de espera. }\end{array}$ \\
\hline Software & $\begin{array}{l}\text { Carrot2, GATE, UIMA, Weka, } \\
\text { NLTK, Torch etc. }\end{array}$ & $\begin{array}{l}\text { Apache Mahout ,ELKI, } \mathrm{H} 2 \mathrm{O}, \\
\text { OpenCV, OpenNN, } \\
\text { MATLAB etc. }\end{array}$ \\
\hline
\end{tabular}

Tabla 7 Diferencias DM y ML-Fuente: Elaboración Propia

Se concluye que el Data Mining y el Machine Learning se complementan, ya que el primero es utilizado para identificar patrones y reglas que sirvan para una predicción, el segundo se encargada de mejorar el nivel de predicción mediante el aprendizaje automático a partir de los patrones identificados previamente. 


\section{CAPÍTULO3: Estado del Arte}

El presente capítulo muestra los resultados de esfuerzos previos relacionados con el presente proyecto de investigación, indicando en cada uno de estos, dicha relación y el rubro en el que se fue implementado. Permite rastrear el desarrollo del tema de investigación desde distintos aspectos, entender cómo se encuentra en la actualidad y tener una visión más clara de lo que se puede desarrollar. 


\section{Resumen de los casos de éxito en la implementación de Data Mining}

La capacidad de procesar gran cantidad de data, mediante el uso de Data Mining, ayuda a poder identificar patrones y comportamientos en basándose en ciertos criterios como: dificultad de curso, número de veces que se llevó un curso, notas.

En esta sección se describirán las investigaciones realizadas previamente, las cuales sirven de complemento a la propuesta del proyecto. Por ello, el presente estado del arte tratará sobre investigaciones del uso de técnicas y herramientas de minería de datos orientadas a educación, con la finalidad de familiarizarse con la metodología empleada en ellas, la cual es el proceso de extracción de conocimiento o "Knowledge Discovery in Databases" (KDD).

Una vez que se ha implementado un proyecto orientado a educación con los modelos y pasos adecuados. Se planteará una propuesta de valor a la escuela con el objetivo de que sirva como referencia para futuros proyectos.

$\mathrm{Al}$ obtener esta información se iniciará el proceso de KDD, identificar los patrones y plantear propuestas en base a lo obtenido.

\section{Recommendation in Highter Education Using Data Mining Techniques (2009)}

Uno de los principales problemas que se les presenta a los estudiantes universitarios es tomar la decisión correcta en relación a su itinerario académico basado en información disponible (por ejemplo cursos, horarios, secciones, salones de clase y profesores). En este contexto, este informe propuso el uso de sistemas de recomendación basados en técnicas de minería de datos para ayudar al estudiante a tomar decisiones en su vida académica. 


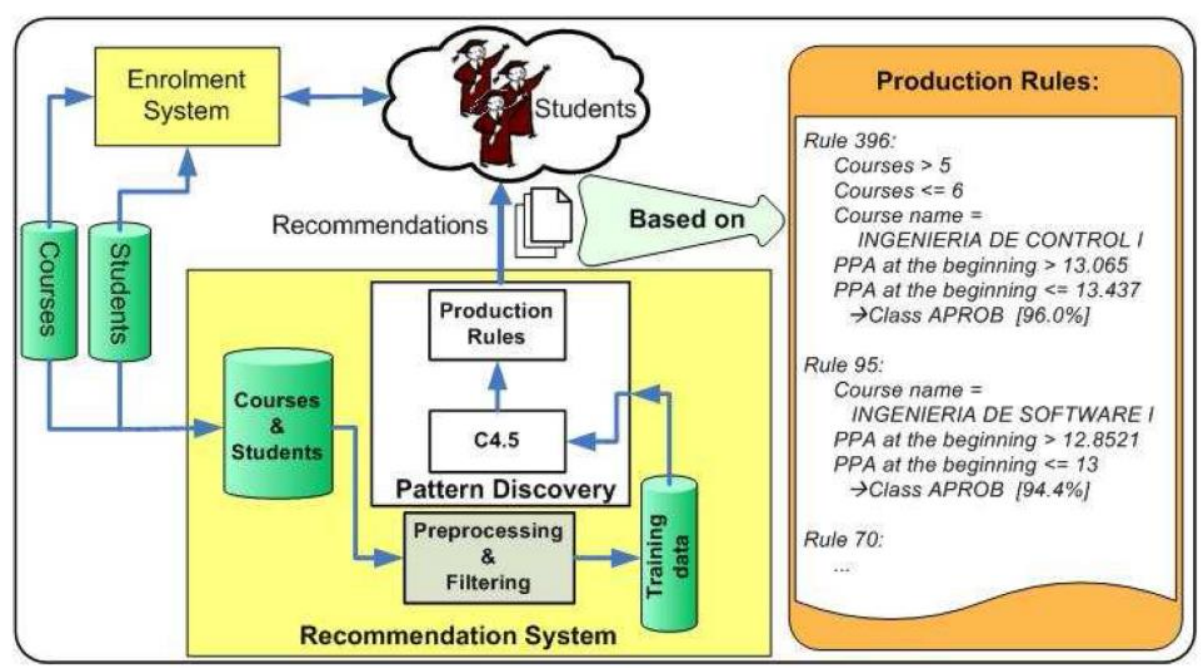

Ilustración 11 Arquitectura del sistema de recomendación

Fuente: EDUCATIONAL DATA MINING (2009)

Específicamente, brindar soporte al estudiante para tomar la mejor decisión respecto a cuantos o a que cursos matricularse, teniendo como base historial de su situación académica $^{36}$. Para este propósito, se tuvo que analizar data real correspondiente a 7 años de matrículas de estudiantes de la escuela. Basado en este análisis se desarrolló un sistema de recomendación basado en Data Mining para la ayuda de toma de decisiones a estudiantes, utilizando el algoritmo C4.5 y usando una variante de la técnica de validación CrossValidation llamada $k$-fold.

A lo largo del estudio, se logró generar cuatro corridas del algoritmo. Cada una dio diferentes resultados. Esto ayudo a modificar los datos de entrada del algoritmo para mejorar su nivel de predicción, el cual llego a un $77.3 \%$ de aciertos. Lograron concluir que con la ayuda de las herramientas de Data Mining se puede apoyar a los alumnos a tomar mejores decisiones al momento de matricularse en el ciclo académico y no solo por factores subjetivos. Finalmente, pudieron observar que la información obtenida incluso podría ayudar a que se detecten patrones que ayuden a mejorar la currícula de los cursos dictados en las universidades.

Dicho estudio, muestra que para el escenario de la educación, el uso del algoritmo de árboles de decisión y la técnica de validación de cross-validation es recomendable ya que con una adecuada metodología se puede llegar a niveles altos de predicción.

${ }^{36}$ Cfr.EDUCATIONAL DATA MINING (2009) 


\section{A case Study: Data Mining Applied to Student Enrollment (2010)}

Los estudiantes universitarios se enfrentan a muchos problemas en su vida universitaria, y uno de ellos se presenta al momento de elegir los cursos en los que desean matricularse. En este contexto, este artículo presenta un sistema de recomendación basado en minería de datos para crear conciencia de la dificultad y cantidad de carga de trabajo que implica un conjunto seleccionado de cursos.

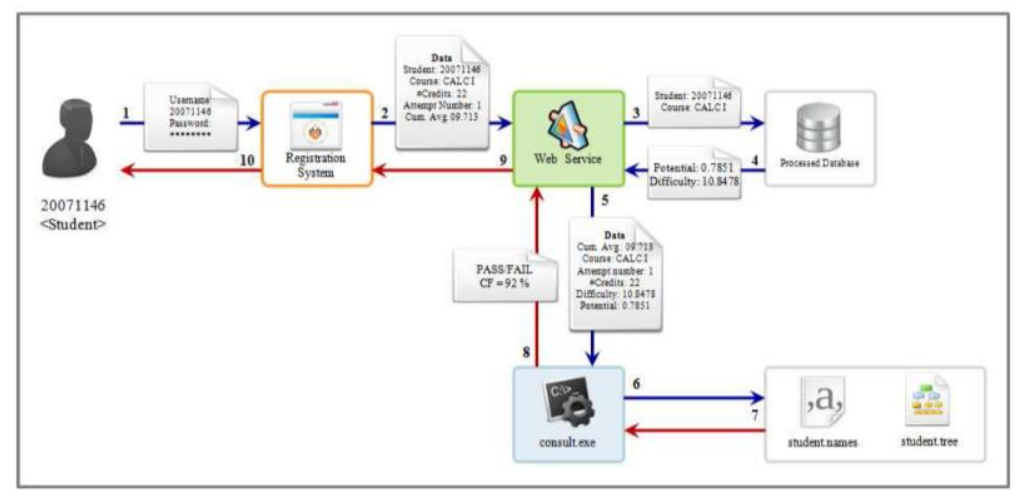

Ilustración 12 Diagrama de flujo del sistema de recomendación

Fuente: EDUCATIONAL DATA MINING (2010)

Para este propósito, en este trabajo se describe la generación de variables específicas de dominio que son capaces de representar el rendimiento pasado del estudiante y se tiene como objetivo mejorar su rendimiento en general, mediante la reducción del índice de decisiones de matrícula equivocadas ${ }^{37}$. Se usó el algoritmo C4.5 y usa una metodología CRISP-DM.

Al terminar el estudio, se pudo concluir que un sistema de recomendación en la que el alumno puede visualizar en tiempo real si lograría pasar un curso antes de llevarlo; ayudaría a concientizar al estudiante de las habilidades que posee para ciertas áreas de estudios y de este modo poder tomar estrategias de estudio y/o al momento de la matrícula.

Dicho paper, demuestra que las técnicas de Data Mining se pueden orientar al campo de la educación universitaria mientras que se obtenga una técnica adecuada de entrenamiento y validación.

\footnotetext{
${ }^{37}$ Cfr. EDUCATIONAL DATA MINING 2010
} 


\section{Data Mining Applications: A comparative Study for Predicting Student's performance (2012)}

La minería de datos está tomando presencia en casi todas las aplicaciones del mundo real. Los arboles de decisión son tan populares porque ellos producen reglas de clasificación que son fáciles de interpretar que otros métodos de clasificación.

Este artículo propone incrementar la calidad de la educación. Esto se logrará cuando las instituciones educativas utilicen la minería de datos para la toma de decisiones en el sistema educacional. Árboles de decisión es uno de los algoritmos más utilizados en los métodos de aprendizaje supervisado para la exploración de data basada en la técnica divide y vencerás. Este informe estudia el uso de árboles de decisión en minería de datos educacional. Estos árboles son aplicados sobre el rendimiento del pasado de los estudiantes para generar modelos, los cuales pueden ser usados para predecir el rendimiento de dichos estudiantes. Esto ayudará a identificar posibles retiros y alumnos que necesitan especial atención permitiendo a los maestros dar la asesoría necesaria ${ }^{38}$.

En dicha investigación se usó la metodología KDD, la herramienta KDD Tools utilizar un algoritmo de aprendizaje supervisado. El algoritmo empleado fue el de Árboles de Decisión, ya que es el más utilizado y los experimentos son conducidos a encontrar el mejor clasificador para la data de estudiantes, usada para predecir el rendimiento de los alumnos al final del semestre.

\section{Mining Student Data Using Decision Trees (2006)}

El rendimiento de los estudiantes en los cursos universitarios es de gran preocupación para las gestiones de educación superior donde varios factores pueden afectar al rendimiento de los estudiantes. Este trabajo es un intento de utilizar los procesos de minería de datos, en particular la clasificación, para ayudar en la mejora de la calidad del sistema de educación superior mediante la evaluación de datos de los estudiantes para estudiar los principales atributos que pueden afectar el desempeño de los estudiantes en los cursos. Para este propósito, el marco CRISP para minería de datos se utiliza para datos académicos relacionados estudiantiles minería. El proceso de generación de regla de clasificación se basa en el árbol de decisión como un método de clasificación donde se estudian y se evaluaron

\footnotetext{
${ }^{38}$ Cfr. KUM AR 2012
} 
las reglas generadas. Un sistema que facilita el uso de las reglas generadas se construye lo que permite a los estudiantes para predecir la nota final en un curso de estudio ${ }^{39}$.

En este artículo se analiza diferentes técnicas de minería de datos que se utilizan en la minería de datos orientado a educación. Entre los algoritmos de clasificación utilizados en este experimento encontramos C4.5, ID3 y Bayes NAIVE. Otros aspectos encontrados, son las variables utilizadas en la predicción, ya que esta información del estudiante es utilizada para predecir el rendimiento de un alumno.

\section{Uncovering Hidden Information within University's Student Enrollment Data Using Data Mining (2009)}

Hasta la fecha, las organizaciones de educación superior se colocan en un entorno competitivo muy alto. Para seguir siendo competitivos, un enfoque es hacer frente a los desafíos de los estudiantes y de administración a través del análisis y presentación de datos o minería de datos ${ }^{40}$. En este artículo se propone la aplicación de tres algoritmos de minería de datos: árboles de decisión, redes neuronales y regresión lineal.

El objetivo de esta investigación fue obtener la técnica con mayor precisión y menor porcentaje de error al analizar los procesos de matrícula de la Universidad de Sebha en Libia.

Se utilizaron dos enfoques principales en este estudio, a saber, los enfoques descriptivos y predictivos de los estudiantes. El análisis de agrupamiento se realizó para agrupar los datos en grupos en base a sus similitudes. El estudio muestra que la red neuronal obtiene la máxima precisión los resultados de las tres técnicas de los estudiantes. ${ }^{41}$

\section{A Data Mining Approach to Recommend Learning Paths based on Academic Performance}

Varias técnicas de minería de datos fueron utilizadas en este artículo, dentro de las cuales podemos destacar C4.5.

El objetivo de este experimento fue utilizar data real y realizar predicciones de rendimie nto de los alumnos en base a su historial académico. Una vez realizada la predicción se propuso

\footnotetext{
${ }^{39}$ Cfr. AL-RADAIDEH 2006

${ }^{40}$ Cfr. SIRAI 2009

${ }^{41}$ Cfr. SIRAI 2009
} 
la implementación de un sistema de recomendación de matrícula a los alumnos de dicha institución educativa.

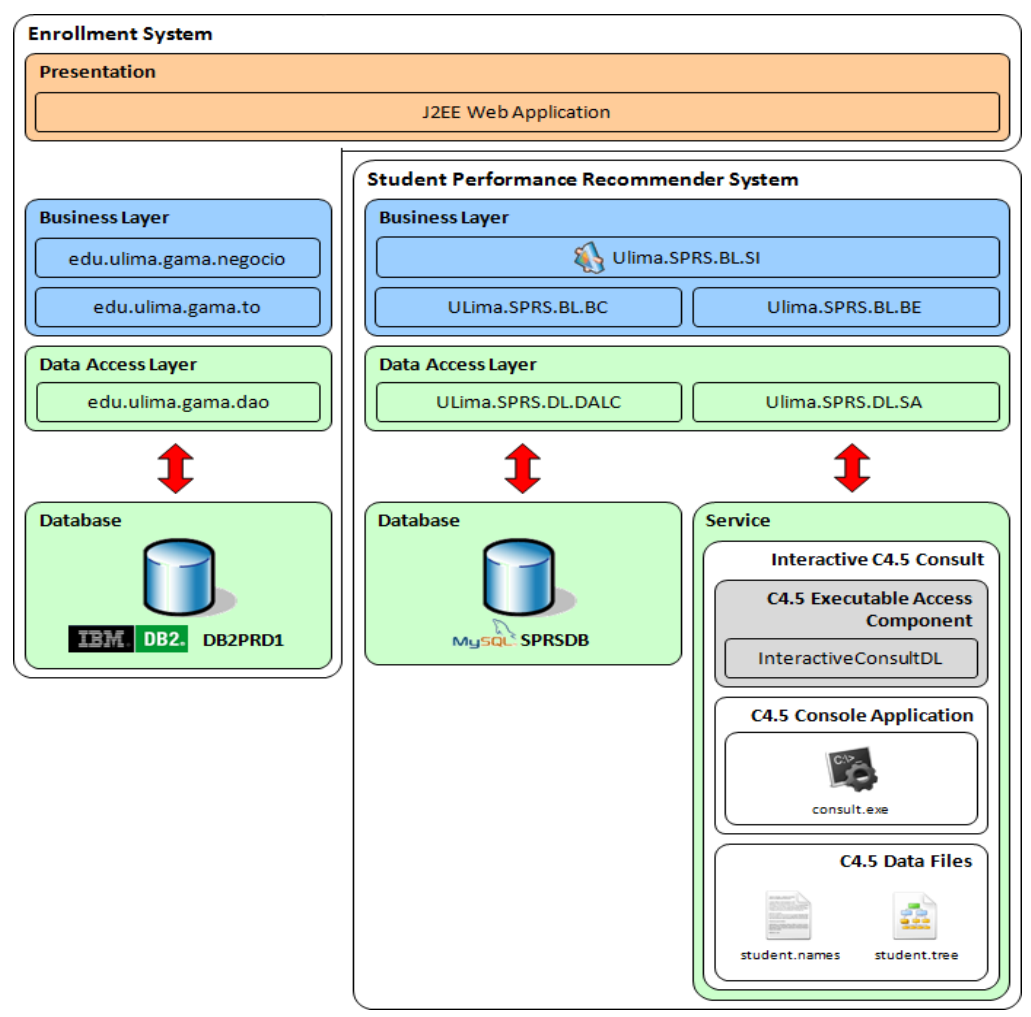

Ilustración 13 Enrollment System Architecture

Fuente: A Data Mining Approach to Recommend Learning Paths based on Academic Performance

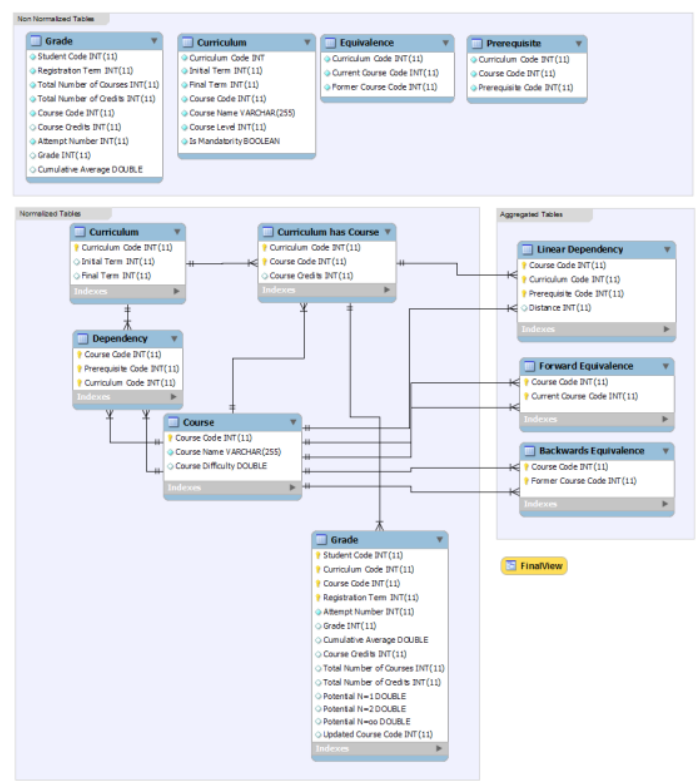

Ilustración 14 Entity Relationship Model 
Fuente: A Data Mining Approach to Recommend Learning Paths based on Academic Performance 


\section{CAPÍTULO 4: Desarrollo del Proyecto}

En el presente capítulo se describe el desarrollo del proyecto, la metodología a utilizar, se detalla las fases de dicha metodología y el proceso a seguir para la correcta implementación del modelo. 
En este capítulo se utilizará la metodología de Mineria de Datos KDD en el proyecto de tesis "Técnicas de inferencias, predicción y minería de datos".

Para lograr el objetivo, se utilizó las herramientas Microsoft SQL Server 2014, la suite ofimática Microsoft Office 2013 y para realizar el análisis de información se ha utilizado la herramienta Data Tools, la cual contiene un conjunto de algoritmos que serán de ayuda al proyecto.

La información utilizada para el proyecto pertenece a los alumnos, cursos y secciones de la Escuela de Ingeniería de Sistemas y Computación de la Facultad de Ingeniería de la UPC correspondientes del ciclo 2009-I al 2014-I.

Con dicha información y con el análisis de las diferentes herramientas y la aplicación de los estudios revisados en el capítulo 3. Se decidió utilizar la metodología KDD para poder llegar al objetivo del proyecto.

A continuación, se presenta la metodología KDD dividida en 3 fases:

Extracción de la data: Extraer la data almacenada en las bases de datos de la universidad u obtener la información a analizar por algún otro sistema de la universidad.

\section{Selección, Transformación y Depuración de data:}

- Normalización de la data: Se estandarizan las variables a utilizar.

- Agregación de la data: Se crean las tablas donde se almacenará la información para su posterior análisis.

- Generación de la data: Se crean los campos calculados.

- Filtrado de la data: En este punto se filtra solo los campos que brindan valor al modelo.

- Selección de atributos: Se definen los atributos que serán analizados en la minería de datos.

- Data Mining: En esta Fase se utiliza el algoritmo elegido (Árboles de Decisiones) aplicado al modelo desarrollado previamente con la data recopilada y transformada. 


\section{Extracción de la data}

Según el alcance del proyecto, se extrajo la información académica de los alumnos de la escuela de Ingeniera de Sistemas y Computación. Para ello, se obtuvo el apoyo de los coordinadores de la carrera ya que solo ellos tienen acceso a la información de los alumnos.

Luego, se obtuvo la información correspondiente entre los ciclos 2009-I y 2014-II en archivos con la extensión ".asp”. A continuación se muestra el detalle de la información obtenida:

- "Notas por Curso y Sección": Contiene información de las secciones de los cursos y las notas de los alumnos matriculados en dichos cursos.

- “Alumnos Matriculados por Ciclo": Muestra información de los alumnos matriculados en el ciclo seleccionado.

- "Malla Curricular": Muestra información de los cursos pertenecientes a una currícula en específico.

Finalmente se utilizó la herramienta Microsoft Office para visualizar la información obtenida y determinar cuáles serían los valores relevantes para poder crear la Base de Datos del modelo de minería de datos.

\section{Diagrama de la base de datos}

En este punto se analiza la información obtenida y se determina la estructura de la Base de Datos que el algoritmo utiliza para predecir los resultados. Para lo cual, se determinó crear cinco (05) tablas principales que contienen lo siguiente:

- Tabla Curso: Esta tabla contiene la información de los cursos de las carreras de la Escuela de Ingeniería de Sistemas y Computación (código, nombre del curso, descripción, etc.)

- Tabla Alumno: Contiene la información de los alumnos que se encuentran matriculados en una de las carreras de la Escuela de Ingeniería de Sistemas y Computación (código, nombre, edad, carrera, ciclo matriculado, etc.)

- Tabla Curricula: La tabla contiene información de las diferentes curriculas que estuvieron vigentes entre el periodo de extracción (2009-I a 2014-II).Tabla Preliminar: Contiene información de las notas obtenidas por los alumnos en los diferentes ciclos (sección, curso, profesor, nota, ciclo del curso, etc.) 
- Tabla VistaCompleta: Finalmente, se creó la tabla que contiene toda la información necesaria para que el algoritmo se alimente y puede obtener los resultados esperados en este proyecto.

A continuación, se presenta el diagrama de la base de datos con la dependencia entre tablas y sus campos:

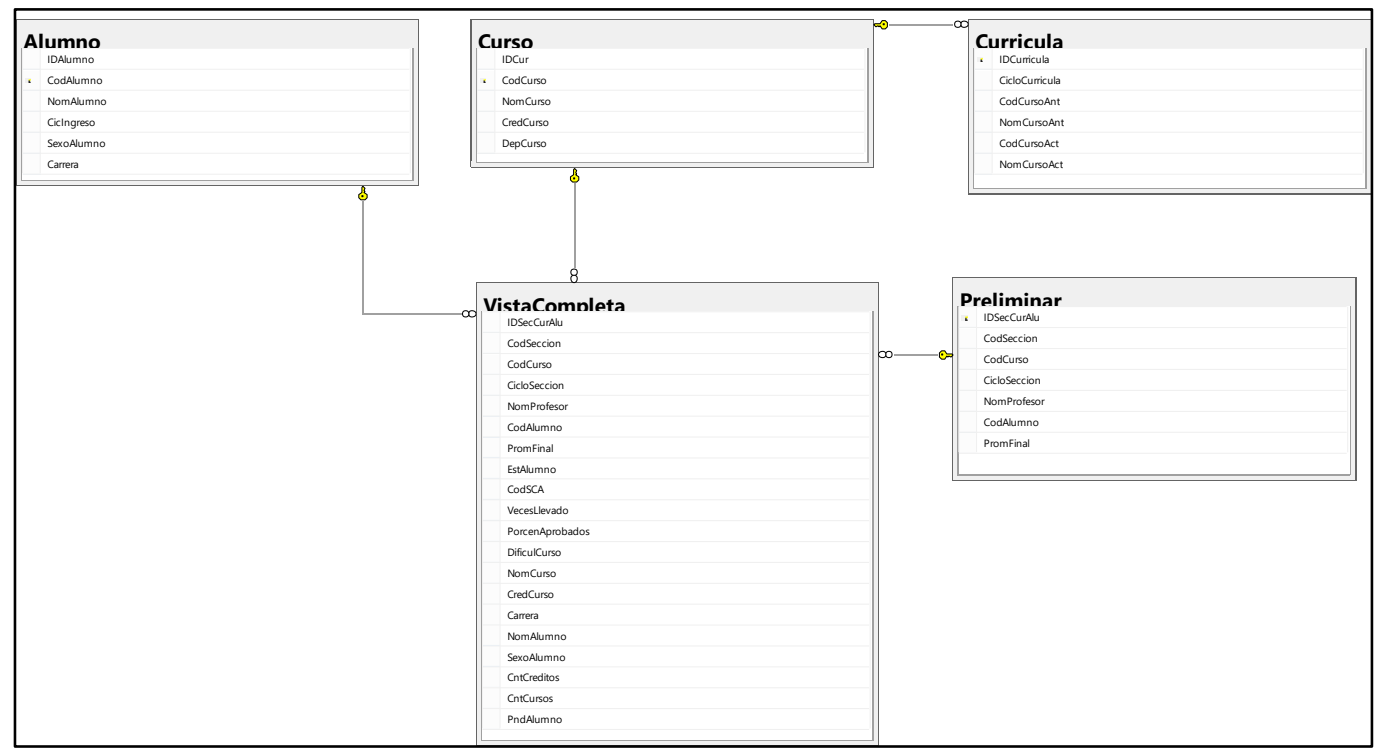

Ilustración 15 Diagrama de BD

Fuente: Elaboración Propia

\section{Depuración, Selección y Transformación de data}

En esta fase, el objetivo es seleccionar, transformar y crear información en base a la data extraída de los alumnos de la EISC, con el fin que sea utilizada como input para el modelo de datos. Para ello se depura la data, se selecciona los datos que serán relevantes para el modelo y se genera nueva información para obtener las variables necesarias que serán utilizadas en la minería de datos.

\section{Normalización de la data}

En esta etapa se realiza la normalización de la data, es decir estandarizar las variables con la finalidad de que no exista incoherencias en una posterior etapa como valores null o campos en blanco y de este modo estandarizar la data. 


\begin{tabular}{|l|l|}
\hline Revisar "Nulls" & Validar los campos con valores nulos. \\
\hline Rellenar Campos en blanco & $\begin{array}{l}\text { Completar los registros cuyos campos estén } \\
\text { en blanco. Se llenaran con valores coherentes } \\
\text { según el campo. }\end{array}$ \\
\hline Revisar inconsistencias & $\begin{array}{l}\text { Validar la información contenida en las tablas } \\
\text { para evitar futuros inconvenientes como } \\
\text { tildes o caracteres especiales. }\end{array}$ \\
\hline Limpiar variables & $\begin{array}{l}\text { Se eliminarán registros de alumnos con } \\
\text { códigos que no pertenezcan al rango [2009- } \\
\text { I;2014-II] y los alumnos con estado } \\
\text { RETIRADO o DPI }\end{array}$ \\
\hline
\end{tabular}

Tabla 8 Normalización

Fuente: Elaboración Propia

\section{Agregación de la data}

En esta etapa se seleccionan algunas variables del universo, con la finalidad de que sirvan como inputs en el modelo. A continuación, se muestran las variables seleccionadas, además de las tablas que se utilizarán para la minería de datos.

\begin{tabular}{|c|c|c|c|c|}
\hline $\begin{array}{l}\text { Métod } \\
\text { o }\end{array}$ & Tabla & Variable & Descripción & Posibles Valores \\
\hline \multirow{6}{*}{$\begin{array}{l}\text { Variabl } \\
\text { es } \\
\text { directas } \\
\text { obtiene se } \\
\text { n de las } \\
\text { fuentes }\end{array}$} & Preliminar & CodSeccion & $\begin{array}{l}\text { Código de la } \\
\text { Sección del Curso }\end{array}$ & $\begin{array}{l}\text { \{AD99,SI138,SI182,MA } \\
231\}\end{array}$ \\
\hline & Curso & CodCurso & Código del Curso & $\begin{array}{l}\{\mathrm{A} 101, \mathrm{~A} 201, \mathrm{~S} 001, \mathrm{D} 206 \\
\}\end{array}$ \\
\hline & Preliminar & CicloSeccion & $\begin{array}{l}\text { Ciclo en que se } \\
\text { dictó la sección }\end{array}$ & $\begin{array}{l}\{2009-\mathrm{I}, 2010-\mathrm{II}, 2011- \\
\text { I,2012-II }\}\end{array}$ \\
\hline & Preliminar & NomProfesor & $\begin{array}{l}\text { Nombre del } \\
\text { profesor del Curso } \\
\text { en esa sección }\end{array}$ & $\begin{array}{l}\text { \{Chaupis, Abel; Parasi, } \\
\text { Víctor; } \\
\text { Alfredo }\end{array}$ \\
\hline & Curso & CodAlumno & Código del alumno & $\begin{array}{l}\{200910033, \\
201020059,201110324, \\
201121234\}\end{array}$ \\
\hline & Preliminar & PromFinal & $\begin{array}{l}\text { Promedio Final del } \\
\text { alumno en dicho } \\
\text { curso }\end{array}$ & $\{16,15,18,11,12\}$ \\
\hline
\end{tabular}




\begin{tabular}{|c|c|c|c|c|}
\hline $\begin{array}{l}\text { Métod } \\
\text { o }\end{array}$ & Tabla & Variable & Descripción & Posibles Valores \\
\hline & Curso & NomCurso & Nombre del Curso & $\begin{array}{l}\text { \{Programación 1, Base } \\
\text { de Datos, Estadística } 1\}\end{array}$ \\
\hline & Curricula & $\begin{array}{l}\text { CicloCurricul } \\
\text { a }\end{array}$ & Ciclo de la currícula & $\begin{array}{l}\{2009-\mathrm{I}, 2010-\mathrm{II}, 2011- \\
\mathrm{I}, 2012-\mathrm{II}\}\end{array}$ \\
\hline & Curricula & CodCursoAnt & $\begin{array}{l}\text { Código Anterior del } \\
\text { Curso }\end{array}$ & $\begin{array}{l}\{\mathrm{D} 102, \mathrm{HU} 003, \text { SI92,MA } \\
261\}\end{array}$ \\
\hline & Curricula & $\begin{array}{l}\text { NomCursoA } \\
\text { nt }\end{array}$ & $\begin{array}{ll}\text { Nombre } & \text { Anterior } \\
\text { del Curso } & \end{array}$ & $\begin{array}{lll}\text { Historia } & \text { del } & \text { Perú, } \\
\text { Matemática } & \text { Básica para } \\
\text { Ing.\} } & & \end{array}$ \\
\hline & Curso & CredCurso & Crédito del curso & $\{4,5,6,2\}$ \\
\hline & Alumno & Carrera & Carrera del Alumno & $\begin{array}{l}\text { \{Ingeniería de Sistemas } \\
\text { de } \\
\text { Ingeniería de Software }\}\end{array}$ \\
\hline & Alumno & NomAlumno & Nombre del alumno & $\begin{array}{l}\text { \{Apolaya Torres, Carlos } \\
\text { Humberto; } \\
\text { Diaz, Adolfo }\end{array}$ \\
\hline & Alumno & SexoAlumno & Sexo del Alumno & $\{\mathrm{M}, \mathrm{F}\}$ \\
\hline
\end{tabular}

Tabla 9 Campos Agregados

Fuente: Elaboración Propia

\section{Generación de la data}

En esta etapa, se genera nueva información con la data ya existente, transformándola y creando nuevas variables que servirán para cumplir con el objetivo del modelo de minería de datos. A continuación, se muestra las nuevas variables:

\begin{tabular}{|c|c|c|c|c|}
\hline Método & Tabla & Variable & Descripción & Posibles Valores \\
\hline \multirow{2}{*}{$\begin{array}{l}\text { Se } \\
\text { obtienen } \\
\text { en base a } \\
\text { las } \\
\text { variables } \\
\text { directas }\end{array}$} & $\begin{array}{l}\text { VistaComplet } \\
\text { a }\end{array}$ & CntCreditos & $\begin{array}{l}\text { Cantidad de Créditos } \\
\text { que lleva el alumno } \\
\text { en el presente ciclo }\end{array}$ & $\{14,15,16,21,25\}$ \\
\hline & $\begin{array}{l}\text { VistaComplet } \\
\text { a }\end{array}$ & CntCursos & $\begin{array}{l}\text { Cantidad de Cursos } \\
\text { que lleva el Alumno } \\
\text { en el presente ciclo }\end{array}$ & $\{4,7,6,5,3\}$ \\
\hline
\end{tabular}




\begin{tabular}{|c|c|c|c|}
\hline $\begin{array}{l}\text { VistaComplet } \\
\text { a }\end{array}$ & PndAlumno & $\begin{array}{l}\text { Promedio Ponderado } \\
\text { del Alumno }\end{array}$ & $\begin{array}{l}\{16,15.25,18,11, \\
12.49\}\end{array}$ \\
\hline $\begin{array}{l}\text { VistaComplet } \\
\text { a }\end{array}$ & EstAlumno & Estado del alumno & $\begin{array}{l}\text { \{APROBADO, } \\
\text { DESAPROBADO }\}\end{array}$ \\
\hline $\begin{array}{l}\text { VistaComplet } \\
\text { a }\end{array}$ & CodSCA & $\begin{array}{ll}\text { Concatenado } & \text { de } \\
\text { Curso-Ciclo- } & \\
\text { Profesor } & \end{array}$ & $\begin{array}{l}\text { \{MA1762009- } \\
\text { IINOVOA, HU032009- } \\
\text { IIPENA, HU1592009- } \\
\text { IIGARAY\} }\end{array}$ \\
\hline $\begin{array}{l}\text { VistaComplet } \\
\text { a }\end{array}$ & $\begin{array}{l}\text { VecesLlevad } \\
\text { o }\end{array}$ & $\begin{array}{l}\text { Número de veces que } \\
\text { el alumno ha llevado } \\
\text { el curso }\end{array}$ & $\{1,3,2,4\}$ \\
\hline $\begin{array}{l}\text { VistaComplet } \\
\text { a }\end{array}$ & $\begin{array}{l}\text { PorcenAprob } \\
\text { ados }\end{array}$ & $\begin{array}{l}\text { Porcentaje de } \\
\text { aprobados de una } \\
\text { Sección de un Curso }\end{array}$ & $\begin{array}{lll}\{50.0, & 67.8, & 43.6, \\
24,25\} & & \end{array}$ \\
\hline $\begin{array}{l}\text { VistaComplet } \\
\text { a }\end{array}$ & DificulC urso & Dificultado del Curso & $\begin{array}{lll}\{10.0, & 10.88, & 16.50, \\
17.25\} & & \end{array}$ \\
\hline
\end{tabular}

Tabla 10 Generación de Data

Fuente: Elaboración Propia

\subsubsection{Data Mining}

En esta fase, se seleccionó las variables consideradas para el modelo y luego se ingresó a la herramienta (Data Tools de Microsoft) para que la data sea procesada por el algoritmo seleccionado (Árboles de Decisión) y posteriormente validada (Cross Validation 10-Fold).

Para ello se hace un análisis de las variables que afectan al modelo y se decidió seleccionar las siguientes con los siguientes tipos de datos presentados en la herramienta:

\begin{tabular}{|l|l|}
\hline \multicolumn{2}{|l|}{ Variable } \\
\hline CntCreditos \\
\hline CntCursos & input \\
\hline CodAlumno & ignore \\
\hline CodCurso & ignore \\
\hline
\end{tabular}




\begin{tabular}{|l|l|} 
CredCurso & input \\
\hline DificulCurso & input \\
\hline EstAlumno & PredictOnly \\
\hline IDSecCurAlu & key \\
\hline NomAlumno & ignore \\
\hline NomCurso & ignore \\
\hline PndAlumno & input \\
\hline PorecAprobados & input \\
\hline VecesLlevado & input \\
\hline
\end{tabular}

Tabla 11 Variables escogidas

Fuente: Elaboración Propia

Donde:

- PredictOnly: Es la variable a que se desea predecir.

- Input: Son aquellas variables que afectan directamente al resultado que se quiere obtener ya que el algoritmo se alimenta de dicha información.

- Key: Se utiliza como identificador único.

- Ignore: Son variables que no afectan al algoritmo y su función es complementar los resultados obtenidos con información ya existente.

Luego de ejecutar la herramienta se genera la validación de los resultados que sirve para saber el porcentaje error que tiene el modelo

Para ello se utiliza la matriz de confusión: 


\section{Estado real}

TP

FP

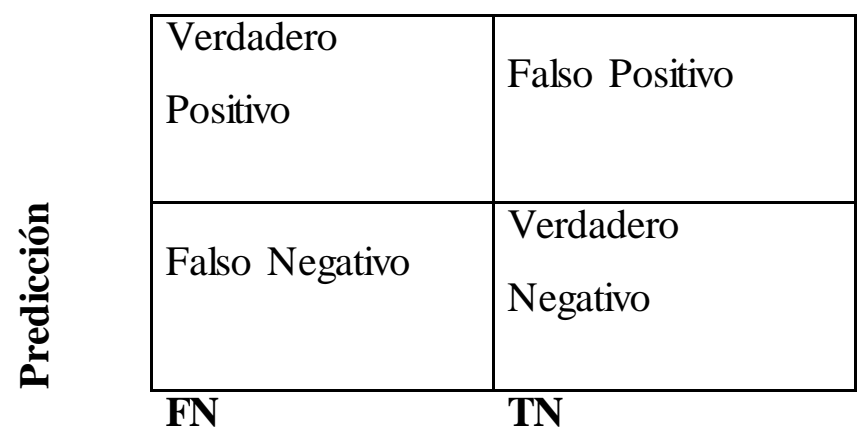

Ilustración 16 Matriz de Confusión

Fuente: Elaboración Propia

A continuación, se muestra el detalla de cada una de las variables de la fórmula del porcentaje de error.

\begin{tabular}{|c|c|c|c|c|}
\hline Variable & Descripción & Predicción & Predicho & Real \\
\hline TP & verdadero negativo & Correcta & Desaprobado & Desaprobado \\
\hline TN & verdadero positivo & Correcta & Aprobado & Aprobado \\
\hline FP & falso negativo & Incorrecta & Desaprobado & Aprobado \\
\hline FN & falso positivo & Incorrecta & Aprobado & Desaprobado \\
\hline
\end{tabular}

Tabla 12 Matriz de confusión

Fuente: Elaboración Propia

Finalmente, se obtuvo el porcentaje de error luego de la ejecución del algoritmo y se pudo apreciar los resultados obtenidos para su posterior anális is y mejora del modelo.

Luego de la ejecución del proyecto se concluye que es necesario tener una adecuada documentación de las fases a considerar para el modelo. Asimismo, el modelo debe ser lo suficientemente flexible para permitir cambios luego de cada procesamiento de información para que pueda ser mejorado constantemente. Por último, se recomienda cuestionar las variables seleccionadas para el modelo ya que el modelo depende de ellas para tener un mayor porcentaje de acierto. 


\section{CAPÍTULO 5: Continuidad del Proyecto}

El presente capítulo detalla los resultados obtenidos al implementar el modelo, las pruebas realizadas y recomendaciones para la continuidad del proyecto. 
En el presente capítulo se detalla los resultados obtenidos en las ejecuciones del modelo. Además, se muestra los resultados obtenidos al modificar el modelo en base a un nuevo escenario. Finalmente, se presenta la propuesta de la continuidad del proyecto para su posible implementación en un escenario real.

\section{Resultados de la Ejecución del Proyecto}

Luego de ejecutar el modelo de predicción en la herramienta Data Tools, se puede obtener diagramas y resultados en base a la ejecución que facilitan una adecuada interpretación de la data obtenida.

En la primera ejecución se obtuvo el siguiente gráfico se puede apreciar que variables afectan directamente el resultado del proyecto. Lo que permite escoger las más adecuadas para el modelo.

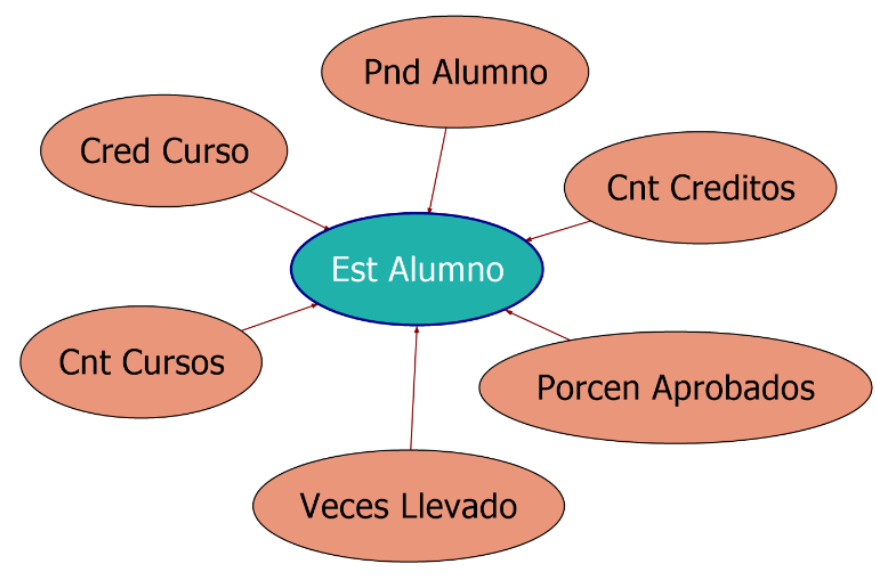

Ilustración 17 Diagrama de Dependencia

Fuente: Elaboración Propia

Además, se utilizó la matriz de confusión para interpretar los resultados obtenidos luego de ejecutar la técnica de validación (Cross Validation 10-Fold) y así, obtener el porcentaje de error del modelo en la primera ejecución. A continuación se presenta los resultados:

\section{Formula Porcentaje de Error}

$$
\% \text { Error }=1-\frac{T P+T N}{T P+T N+F P+F N}
$$

Tabla 13 Formula Porcentaje de Error

Fuente: Elaboración Propia 
El siguiente cuadro presenta a detalle los resultados de la primera ejecución

\begin{tabular}{|c|c|c|}
\hline Diagnostico & Conteo & Porcentaje \\
\hline TN & 317 & $16.31 \%$ \\
\hline TP & 1436 & $73.91 \%$ \\
\hline FN & 72 & $3.71 \%$ \\
\hline FP & 118 & $6.07 \%$ \\
\hline
\end{tabular}

Tabla 14 Resultados Matriz de Confusión

Fuente: Elaboración Propia

En la que el resultado obtenido es:

\begin{tabular}{|c|c|}
\hline \% Error & $9.778693 \%$ \\
\hline \% Aciertos & $90.221307 \%$ \\
\hline
\end{tabular}

Tabla 15 Porcentaje de error hallado

Fuente: Elaboración Propia

Luego, se hizo un análisis de cada uno de los ciclos para observar la consistencia y el comportamiento de la información extraída. Endicho análisis se obtuvo los siguientes resultados:

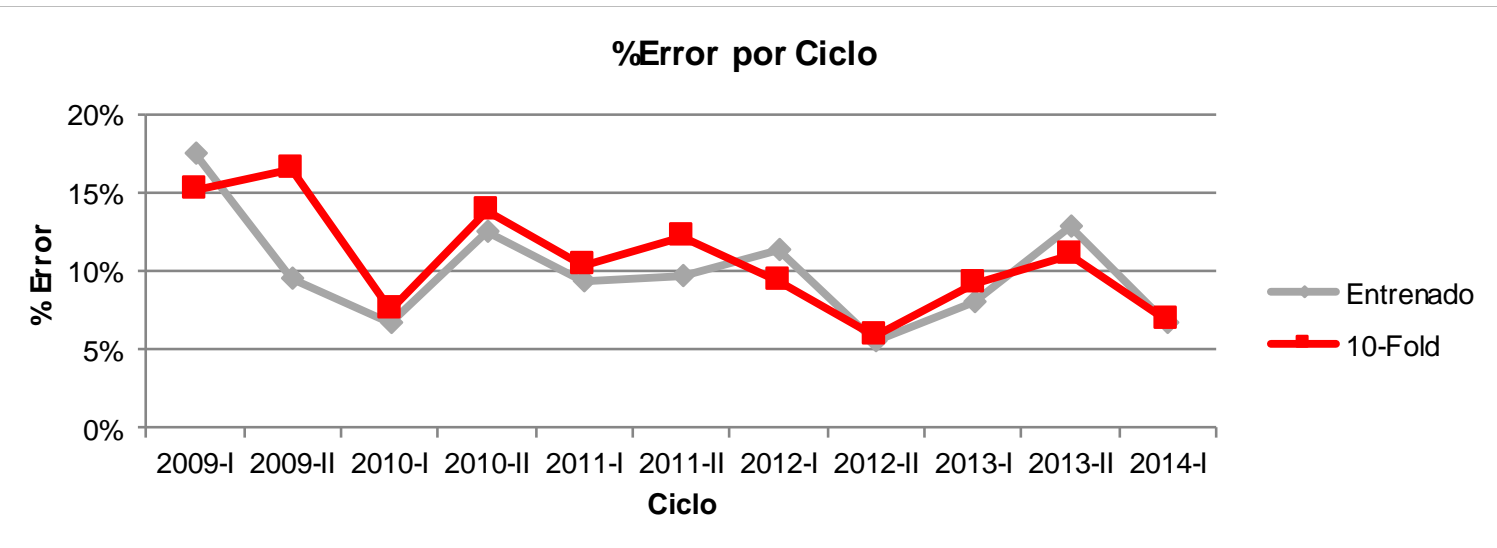

Ilustración 18 Ciclos Errados

Fuente: Elaboración Propia 
Posteriormente, se observó que los resultados de los ciclos 2010-I y 2014-II no se encontraban completos, por lo que fue necesario extraer la información nuevamente.

El siguiente cuadro muestra los resultados obtenidos en el gráfico anteriormente presentado:

\begin{tabular}{|c|c|c|c|}
\hline \multicolumn{4}{|c|}{ \% Error por ciclo } \\
\hline Ciclo & Registros & Entrenado & 10-Fold \\
\hline 2009-I & 861 & $17.441860 \%$ & $15.189873 \%$ \\
\hline 2009-II & 940 & $9.574468 \%$ & $16.470588 \%$ \\
\hline 2010-I & 1943 & $6.701031 \%$ & $7.428571 \%$ \\
\hline 2010-II & 1849 & $12.500000 \%$ & $13.772455 \%$ \\
\hline 2011-I & 2044 & $9.313725 \%$ & $10.326087 \%$ \\
\hline 2011-II & 2193 & $9.589041 \%$ & $12.121212 \%$ \\
\hline 2012-I & 2635 & $11.406844 \%$ & $9.282700 \%$ \\
\hline 2012-II & 1117 & $8.391608 \%$ & $9.302326 \%$ \\
\hline 2013-I & 2899 & $7.958478 \%$ & $9.160305 \%$ \\
\hline 2013-II & 3362 & $11.011905 \%$ & $9.900990 \%$ \\
\hline 2014-I & 3339 & $8.408408 \%$ & $9.666667 \%$ \\
\hline 2014-II & 3661 & $4.885057 \%$ & $4.777070 \%$ \\
\hline
\end{tabular}

Tabla 16 Porcentaje de error por ciclo

Fuente: Elaboración Propia

Luego, se evaluó la mejora del modelo con la agregación de la data de cada ciclo, simulando que el proceso se haya generado a lo largo de 6 años, pero de manera regresiva con el fin de observar si el cambio de datos y variables afectan al modelo de forma positiva o negativa. Obteniendo los siguientes resultados:

\begin{tabular}{|c|c|c|c|c|}
\hline ID & Ciclo & Registros & Entrenado & 10-Fold \\
\hline 1ro & 2014-I & 3339 & 0.084084084 & 0.096666667 \\
\hline
\end{tabular}




\begin{tabular}{|c|c|c|c|c|}
\hline ID & Ciclo & Registros & Entrenado & 10-Fold \\
\hline 2do & 2013-II + 1ro & 6700 & 0.074626866 & 0.097844113 \\
\hline 3 ro & $2013-\mathrm{I}+2 \mathrm{do}$ & 9600 & 0.085416667 & 0.093641618 \\
\hline 4 to & 2012-II + 3ro & 12460 & 0.090690209 & 0.092691622 \\
\hline 5to & $2012-\mathrm{I}+4$ to & 15090 & 0.08880053 & 0.090507726 \\
\hline 6to & 2011-II + 5to & 17280 & 0.089699074 & 0.09125964 \\
\hline $7 \mathrm{mo}$ & 2011-I + 6to & 19330 & 0.093119503 & 0.087981599 \\
\hline $8 \mathrm{vo}$ & $2010-\mathrm{II}+7 \mathrm{mo}$ & 21180 & 0.084513692 & 0.092864638 \\
\hline 9no & $2010-\mathrm{I}+8 \mathrm{vo}$ & 23120 & 0.08650519 & 0.091302259 \\
\hline $10 \mathrm{mo}$ & 2009-II + 9no & 24060 & 0.089775561 & 0.092797784 \\
\hline $11 \mathrm{vo}$ & $2009-\mathrm{I}+10 \mathrm{mo}$ & 24920 & 0.097512039 & 0.093137255 \\
\hline
\end{tabular}

Tabla 17 Porcentaje de error acumulativo

Fuente: Elaboración Propia

Se observa que el modelo se mantiene relativamente constante aún con el aumento de data. Por lo que se puede afirmar que el análisis previo, el cambio de variables, la selección de los campos para el algoritmo es de carácter confiable.

Finalmente se volvió a ejecutar todo el algoritmo y validar el con la técnica de validación, obteniendo los siguientes resultados.

\begin{tabular}{|l|l|l|}
\hline Diagnostico & Conteo & Porcentaje \\
\hline Verdadero negativo & 462 & $16.18 \%$ \\
\hline Verdadero positivo & 2135 & $74.70 \%$ \\
\hline Falso negativo & 113 & $3.95 \%$ \\
\hline Falso positivo & 148 & $5.17 \%$ \\
\hline
\end{tabular}

Tabla 18 Segundo resultados Matriz de Confusión 
Fuente: Elaboración Propia

En la que el resultado obtenido es:

\begin{tabular}{|l|l|}
\hline \%Error & $9.132260 \%$ \\
\hline \%Aciertos & $90.867740 \%$ \\
\hline
\end{tabular}

Tabla 19 Segundo porcentaje de error hallado

Fuente: Elaboración Propia

Luego de obtener los resultados de la última ejecución del modelo se pudo observar las mejores, tal como se observa en el siguiente cuadro:

\begin{tabular}{|l|l|l|}
\hline & $\begin{array}{l}\text { 1ra } \\
\text { Ejecución }\end{array}$ & $\begin{array}{l}\text { 2da } \\
\text { Ejecución }\end{array}$ \\
\hline \% Error & $9.778693 \%$ & $9.132260 \%$ \\
\hline Aciertos & $90.221307 \%$ & $90.867740 \%$ \\
\hline
\end{tabular}

Tabla 20 Comparativo Porcentaje de Error

Fuente: Elaboración Propia

Se puede observar que hubo una mejora del $0.64 \%$ aproximadamente lo cual a un nivel estadístico es significativo.

Finalmente, para validar que el modelo es adecuado se utilizó: 


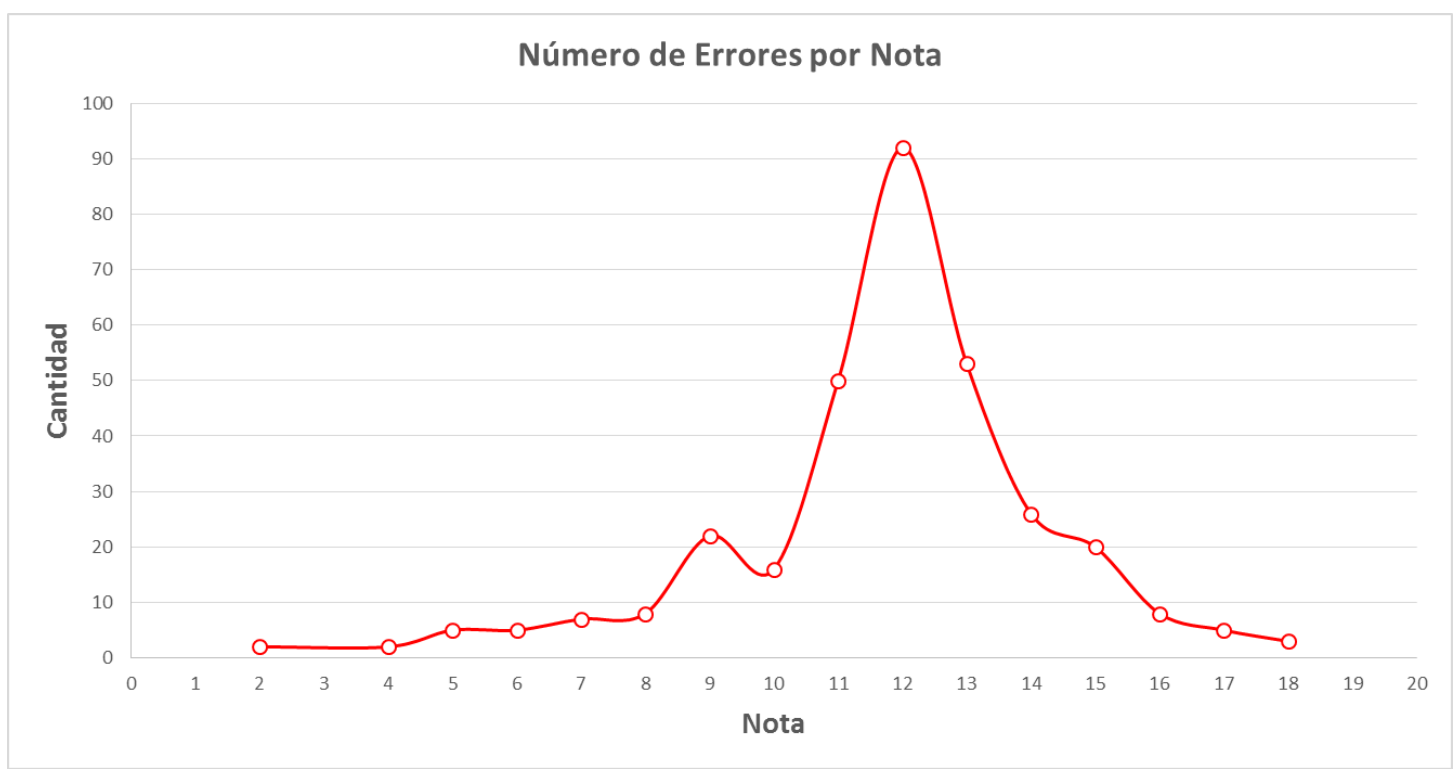

Ilustración 19 Cantidad de errores por nota

Fuente: Elaboración Propia

En el anterior gráfico se observa que la mayoría de los errores encontrados en el modelo de entrenamiento versus el resultado real se concentra entre las notas 10 y 14. Esto se debe a que entre dicho intervalo se encuentra la nota desaprobatoria. También, se puede observar que el punto máximo se encuentra en la nota $12,0.5$ puntos menos que la nota aprobatoria. Dicho gráfico es un sustento de que el modelo está siendo eficiente y consecuente con la información brindada por la escuela.

\section{Propuesta de Continuidad}

\section{Resumen de lo obtenido}

Se recibió una necesidad por parte del Profesor de la escuela de Ingeniería de Sistemas y Computación, Víctor Parasi Falcon, la cual consistía en lo siguiente:

Utilizar el modelo para realizar predicciones de rendimiento en alumnos ingresantes (que no cuentan con historial académico previo). Para ello el profesor entrego datos de los alumnos ingresantes del ciclo 2016-I, con el objetivo de predecir si los alumnos aprobarán el curso de "Compresión y producción de Lenguaje 1".

Luego de ingresar los datos entregados por el profesor en el modelo, se modificó las siguientes variables de entrada: 


\begin{tabular}{|c|c|c|}
\hline Variable & Antes & Después \\
\hline CntCreditos & Input & Input \\
\hline CntCursos & Input & Input \\
\hline CodAlumno & Ignore & Ignore \\
\hline CodCurso & Ignore & Ignore \\
\hline CredCurso & Input & Input \\
\hline DificulC urso & Input & No Aplica \\
\hline EstAlumno & PredictOnly & PredictOnly \\
\hline IDSecCurAlu & Key & Key \\
\hline NomAlumno & Ignore & Ignore \\
\hline NomCurso & Ignore & Ignore \\
\hline PndAlumno & Input & No Aplica \\
\hline PorecAprobados & Input & No Aplica \\
\hline VecesLlevado & Input & Input \\
\hline
\end{tabular}

Tabla 21 Variables modificadas

Fuente: Elaboración Propia

Con los resultados se observó lo siguiente:

Al no contar con el historial académico del alumno ingresante, el modelo no podía realizar una predicción acertada.

El modelo realizaba una predicción errada ya que el algoritmo de Árbol de Decisiones optaba por poner la muestra en una rama en la que los alumnos aprobaban de acuerdo a las variables ingresadas. 


\section{Excepciones al Modelo}

Se identificó que el modelo necesita Por otro lado al utilizar el modelo para predecir el rendimiento académico de alumnos con historial académico, este realiza una predicción acorde a lo investigado con las siguientes condiciones:

Se cuente con información histórica del rendimiento del alumno previa al ciclo que se requiere predecir.

El promedio requerido para aprobar un curso siga manteniéndose. (Se requiere un 13 de promedio para aprobar el curso)

Se realice una correcta estandarización entre cursos que hayan cambiado su peso en créditos.

\section{Propuesta 1:}

En base a los resultados obtenidos previamente se puede observar que el modelo de predicción puede ser aplicado en un escenario real, de tal forma que pueda ser utilizado como soporte a las decisiones administrativas de una universidad.

Por lo que se propone una mejora del modelo y su implementación dentro del proceso de matrícula ya que brindaría estadísticos importantes para la universidad y para los alumnos al tomar en cuenta los resultados predichos por la herramienta. Además, al obtener la cantidad de alumnos que puedan aprobar o no un curso en específico, podría ser utilizado para tomar decisiones, tales como:

- La cantidad de profesores a contratar para un curso, pero en el siguiente ciclo.

- La cantidad de tutores a contratar para un curso, pero en el siguiente ciclo.

- El número de secciones que se deben abrir en un ciclo de un curso en específico.

\section{Propuesta 2:}

Por otro lado, la investigación realizada puede ser utilizada por la Escuela de Ingeniería de Sistemas y Computación como input de proyectos de tesis que permitan implementar una solución basándose en el modelo presentado y/o utilizando la metodología KDD. 


\section{$\underline{\text { Recomendaciones para modificar el modelo }}$}

Para mejorar los resultados y que el algoritmo pueda predecir con mayor exactitud el estado aprobatorio de un alumno respecto a un curso, es necesario agregar nuevas variables que no estén relacionadas directamente la vida universitaria, tales como el nivel académico alcanzado por los padres, el lugar de estudios secundarios, los idiomas que el alumno tiene, si proviene de una familia estable, etc. Los cuales son factores que puedan ser analizados por el árbol de predicción y medir que tan útiles pueden ser al modelo propuesto ya que actualmente no se cuenta con dicha información,

Es importante mencionar que sería necesario solicitar acceso a una copia de la información de la base de datos de la universidad ya que la extracción de la data se hace tediosa y poco confiable ya que la red no soporta la descarga de algunos cursos al utilizar el método convencional de descarga desde la intranet de un profesor.

Al automatizar el proceso de carga de información se facilitaría la actualización y mantenimiento del modelo con ayuda de herramientas que permitan acceder a la base de datos de forma segura.

\section{Conclusiones}

Se plantea como continuidad del proyecto la mejora del actual modelo y su futura implementación en el proceso de matrícula.

La mejora del modelo se puede realizar mediante la inclusión de nuevas variables tal como se mencionó previamente o mediante la optimización de sus procesos como por ejemplo el proceso de carga de información. Además este modelo puede ser utilizado por la escuela para identificar cuantas secciones, profesores o tutores serán necesarios en un ciclo en base a la predicción realizada por el modelo.

Su futura implementación en el proceso de matrícula debe ser analizada ya que su inclusión puede ser utilizada para que los alumnos tomen conciencia y se organicen de tal forma que se enfoquen en los cursos que según el modelo pueda predecir que existe el riesgo que desaprueben. 


\section{CAPÍTULO 6: Gestión del Proyecto}

En el presente capítulo se describen los resultados finales en la gestión propia del proyecto, en los aspectos de Resultado Final y las Gestiones de alcance, tiempo, comunicación, recursos humanos y riesgos. 


\section{Producto final}

El producto final es un modelo de minería de datos aplicado al rubro educación. Dicho modelo fue conseguido gracias al apoyo de los coordinadores de la escuela de ingeniería de sistemas y computación.

En el modelo se implementaron técnicas y algoritmos de minería de datos, las cuales identifican patrones y ayudan a predecir el rendimiento académico de los alumnos. Es decir, se puede predecir qué tan probable es que alumnos determinados desaprueben uno o más cursos basándose en su historial académico.

\section{Gestión del Tiempo}

En esta sección se detallarán las actividades realizadas según la planificación de trabajo determinada al inicio del proyecto y se describirán los retrasos y contratiempos que se presentaron.

\begin{tabular}{|l|l|l|l|}
\hline Hito del proyecto & $\begin{array}{l}\text { Fecha } \\
\text { Estimada }\end{array}$ & $\begin{array}{l}\text { Entregables } \\
\text { incluidos }\end{array}$ & Prioridad \\
\hline $\begin{array}{l}\text { Aprobación y Firma del Project } \\
\text { Charter }\end{array}$ & $02 / 09 / 2014$ & Project Charter & Alta \\
\hline $\begin{array}{l}\text { Presentación Plan de Proyecto } \\
\text { ante comité }\end{array}$ & $25 / 09 / 2014$ & $\begin{array}{l}\text { Project Charter, } \\
\text { Cronograma, Plan de } \\
\text { Trabajo }\end{array}$ & Alta \\
\hline $\begin{array}{l}\text { Aprobación resultados de } \\
\text { algoritmo de árboles de Decisión }\end{array}$ & $27 / 09 / 14$ & $\begin{array}{l}\text { Informe de Resultados } \\
\text { del Algoritmo }\end{array}$ & Alta \\
\hline $\begin{array}{l}\text { Presentación avance Estado del } \\
\text { Arte }\end{array}$ & $02 / 10 / 14$ & Estado del Arte & Alta \\
\hline $\begin{array}{l}\text { Presentación Marco Teórico } \\
\text { Aprobación resultados algoritmo } \\
\text { de Bayes Naive }\end{array}$ & $02 / 10 / 14$ & Marco Teórico & Alta \\
\hline $\begin{array}{l}\text { Aprobación resultados de } \\
\text { algoritmo de Clústeres }\end{array}$ & $18 / 10 / 14$ & $\begin{array}{l}\text { Informe de Resultados de Resultados } \\
\text { del Algoritmo }\end{array}$ & Alta \\
\hline $\begin{array}{l}\text { Aprobación resultados de } \\
\text { algoritmo de Asociación }\end{array}$ & $01 / 11 / 14$ & $\begin{array}{l}\text { Informe de Resultados } \\
\text { del Algoritmo }\end{array}$ & Alta \\
\hline $\begin{array}{l}\text { Aprobación resultados de } \\
\text { algoritmo de Serie Temporal }\end{array}$ & $15 / 11 / 14$ & $\begin{array}{l}\text { Paper } \\
\text { investigación final }\end{array}$ & Alta \\
\hline
\end{tabular}




\begin{tabular}{|l|l|l|l|}
\hline Hito del proyecto & $\begin{array}{l}\text { Fecha } \\
\text { Estimada }\end{array}$ & $\begin{array}{l}\text { Entregables } \\
\text { incluidos }\end{array}$ & Prioridad \\
\hline Presentación Estado del Arte & $20 / 11 / 14$ & Estado del Arte & Alta \\
\hline $\begin{array}{l}\text { Aplicación compilada para } \\
\text { consolidar data }\end{array}$ & $26 / 03 / 15$ & Aplicativo & Alta \\
\hline $\begin{array}{l}\text { Data recopilada de Facebook por } \\
\text { medio del aplicativo }\end{array}$ & $16 / 04 / 15$ & Base de Datos & Alta \\
\hline $\begin{array}{l}\text { Data Transformada } \\
\text { Data Mining e }\end{array}$ & $14 / 05 / 15$ & Base de Datos & Alta \\
\hline $\begin{array}{l}\text { Aplicar } \\
\text { Identificar Patrones }\end{array}$ & $05 / 05 / 15$ & Aransformada & Alta \\
\hline $\begin{array}{l}\text { Presentación Memoria ante el } \\
\text { comité }\end{array}$ & $14 / 05 / 15$ & Memoria & Alta \\
\hline Evaluar Resultados & $26 / 05 / 15$ & Reportes e informes & Alta \\
\hline Presentar Algoritmos y rubros & $20 / 06 / 15$ & $\begin{array}{l}\text { Presentar Algoritmos } \\
\text { rubros }\end{array}$ & Alta \\
\hline Presentación del Paper & $02 / 07 / 15$ & Paper & Alta \\
\hline Presentación de la Memoria & $02 / 07 / 15$ & Memoria & Alta \\
\hline Poster & $09 / 07 / 15$ & Alta & \\
\hline
\end{tabular}

Tabla 22 Hitos del Proyecto

Fuente: Elaboración Propia

El alcance del proyecto tiene como objetivo concluir con la propuesta de modelo desarrollado a la largo del proyecto. Sin embargo, se tuvo que modificar las fechas ya que hubo un cambio de alcance del proyecto. Pero se lograron alcanzar las fechas gracias al avance oportuno del proyecto.

\section{Gestión de los Recursos Humanos}

A continuación, se detallará como se desarrolló la gestión de los recursos humanos y los inconvenientes surgidos durante la vida del proyecto.

Durante la primera parte del proyecto no se presentaron mayores contratiempos con respecto a la gestión de los recursos humanos. 
Los jefes de proyecto cumplieron con las actividades de gestión del proyecto de acuerdo a los objetivos planteados $\mathrm{y}$, asimismo, se aseguraron que el cronograma de trabajo se cumpla de acuerdo a lo establecido y, en caso no se pudiese, realizar las coordinaciones necesarias para los cambios y no afectar los objetivos planteados en coordinación con el cliente. Durante la primera etapa de investigación y consolidación, ambos integrantes trabajaron en las actividades de investigación del proyecto.

Al iniciar la segunda etapa del proyecto se realizó un cambio de alcance del proyecto. Adicionalmente, se tuvo que realizar la documentación necesaria para el control de cambios de los documentos involucrados.

Se dio un cambio en los roles de los integrantes del proyecto ya que solo puede haber un jefe de proyecto, por tal motivo se definió el rol de "Jefe de Investigación "al segundo integrante del proyecto.

\section{Gestión de Comunicaciones}

A continuación, se detallarán como se desarrolló la gestión de las comunicaciones y los inconvenientes surgidos.

En la primera etapa del proyecto se trabajó en la empresa virtual Innova TI, en donde se realizaron las comunicaciones por medio de correos en Gmail, llamadas telefónicas y reuniones presenciales durante los horarios de clase.

Adicionalmente, los medios de comunicación establecidos con el cliente fueron: correos por Gmail, correo de la universidad, llamadas telefónicas y reuniones presenciales en horarios que el cliente dispuso durante la semana incluyendo los días sábados y domingos.

En esta segunda etapa, se continuó trabajando en la empresa virtual Innova TI. La comunicación establecida fue correos por Gmail, llamadas telefónicas y reuniones presenciales en los horarios de clases. Los medios de comunicación con el cliente se mantuvieron sin ningún cambio y con la misma fluidez de la primera etapa.

\section{Gestión de los Riesgos}

Los riesgos enfrentados durante el desarrollo del proyecto fueron los siguientes:

- Demora en la realización de los entregables. Existieron retrasos en cuanto a los entregables solicitados por el cliente. 
- Modificación del alcance del proyecto. En base a las reuniones realizadas con el cliente, el alcance del proyecto fue modificado.

- Demora en el desarrollo del proyecto debido a la falta de recurso humano o por poco desenvolvimiento de este. Este riesgo se dio en ambas etapas del proyecto, los recursos de TPD2 no desenvolvían adecuadamente entregando información de poco provecho en ciertas ocasiones.

Las actividades de mitigación fueron las siguientes de acuerdo a cada riesgo enfrentado respectivamente:

Se realizaron reuniones de emergencia entre los miembros del proyecto para cumplir con los entregables solicitados por el cliente.

Se realizó la documentación referente a gestión de cambio, por lo que entrego al profesor gerente y cliente para su respectiva aprobación.

Para el bajo rendimiento de los recursos TDP2, se establecieron evaluaciones de avance durante las horas de clase. A pesar de estas, no en todas las ocasiones se lograba recuperar el tiempo perdido en búsquedas sin resultados. Las continuas evaluaciones lograron alertar sobre los retrasos, sin embargo, se tuvo que recurrir a realizar las búsquedas personalmente para evitar retrasos en el proyecto.

En los escenarios en los que no se disponía de recursos de TDP2, la carga de investigación se distribuía entre ambos integrantes de proyecto.

\section{Lecciones aprendidas}

En esta sección se mencionan las lecciones que se han aprendido a lo largo del desarrollo de la investigación:

Durante la investigación se encontraron fuentes de información en distintos papers de investigación referentes al rubro de educación que apoyaban el uso del algoritmo de árboles de decisión utilizado para generar este modelo de minería de datos.

El alcance puede cambiar con facilidad y para ello es necesario considerar tiempos adecuados de elongación que permitan llegar al objetivo.

El modelo depende mucho de la estructura y consistencia de la data que ingresa, por ello es necesario revisar que la data sea correctamente ingresada y verificada. 
Es necesario tener un adecuado control de cambios para tener mapeados todos los documentos que son afectos por algún cambio efectuado a lo largo del proyecto.

\section{CONCLUSIONES}

- Se obtuvo un porcentaje de error de $9.13 \%$ de la ejecución del algoritmo y se pudo apreciar los resultados obtenidos para su posterior análisis y mejora del modelo.

- Por ultimo, se concluye que es necesario tener una adecuada documentación de las fases a considerar para el modelo. Asimismo, el modelo debe ser lo suficientemente flexible para permitir cambios luego de cada procesamiento de información para que pueda ser mejorado constantemente.

- Ademas, se recomienda cuestionar las variables seleccionadas para el modelo ya que el modelo depende de ellas para tener un mayor porcentaje de acierto. 


\section{Bibliografía}

ADEDOYIN-OLOWE, Marian, MEDHAT, Mohamen (2012) A Survey of Data Mining Techniques for Social Network Analysis (consulta: 12 de octubre del 2014)

AGGARWAL, C. (2011) An Introduction to social networks data analytics. Springer US, Asiahack (2014) (http//asiahack.com/wp-content/uploads/2014/04/356-HEALIN Tshiny.jpg) Sitio web que contiene la imagen (consulta: 15 de octubre del 2014)

CAVIEDES, Andrés y HERNÁNDEZ, Freddy (2013) Algorito Naive Bayes. Presentación PowerPoint (consulta: 28 de Agosto de 2014) (http://es.slideshare.net/kvieds/algoritmo naive-bayes)

CHIECO, Filippo y OTROS (2010) Algoritmo del vecino más cercano aplicado a la web

Filmaffinity.com (consulta: 05 de Septiembre de 2014) (http://www.it.uc3 m.es/jvillena/irc/practicas/10-11/05 mem.pdf)

CHIMBELU, Chiponda (2013) Machine Learning to help doctors predict the success of epilepsy brain surgery. En: DW (consulta: 12 de Septiembre de 2014) (http://www.dw.de/machine-learning-to-help-doctors-predict-the-success-of-epilepsybrain-surgery/a-16991493)

DALTON, Lori y OTROS (2009) Clustering Algorithms: On Learning, Validation, Performance, and Applications to Genomics (consulta: 05 de septiembre de 2014) (http:/www.ncbi.nlm.nih.gov/pmc/articles/PMC2766793/)

DW (2014) (http://www.dw.de/image/0,,16314385_401,00.jpg) Sitio web que contiene la imagen (consulta: 15 de octubre del 2014)

EDUCATIONAL DATA MINING (2009) Recommendation in Higher Education Using Data Mining Techniques 2009

EDUCATIONAL DATA MINING (2010) A Case Study: Data Mining Applied to Student Enrollment 2010

GALÁN, Sergio (2007) Filtrado Colaborativo y Sistemas de Recomendación (consulta: 24 de agosto de 2014) (http://www.it.uc3 m.es/jvillena/irc/practicas/06-07/31.pdf)

GIMENO, Juan (2010) Sistemas de Recomendación. Presentación PowerPoint. (Consulta: 24 de agosto de 2014) (http://es.slideshare.net/jmgimeno/sistemas-de-recomendacin)

GitHub (2013) (http//phdp.github.io/posts/2013-07-05-dtl.html) Sitio web de Philippe Desjardins-Proulx; contiene descripción de machine learning (consulta: 27 de septiembre) GÓMEZ, Vanessa (2012) Sistemas de Recomendación: Filtrado Colaborativo. Presentación PowerPoint. (Consulta: 24 de agosto de 2014) (http://www.tsc.uc3m.es/ migue1/MLG/adjuntos/VanessaRecommender.pdf) 
GONZÁLEZ, Andrés (2014) Conceptos básicos de Machine Learning. En: CleverTask (consulta: 09 de Septiembre) (http//www.clevertask.com/conceptos-basicos-machinelearning/)

GRANGE, Álvaro (2013) Apuntes de Machine Learning. En: Álvaro Brange's Blog (consulta: 09 de Septiembre de 2014) (http://brange.me/2013/07/07/apuntes-de-machinelearning/)

GUERRA, Alejandro (2009) Arboles de Decisión (consulta: 27 de Agosto de 2014) (http://www.uv.mx/aguerra/documents/2009-mpi-12.pdf)

GUTIÉRREZ-OSUNA, RICARDO (2014) Leave-one-out Cross Validation (consulta 15 de Septiembre) (http://courses.cs.tamu.edu/rgutier/ceg499_s02/113.pdf)

HAMILTON, Laura (2014) Six Novel Machine Learning Applications (consulta: 12 de Septiembre) (http://www.forbes.com/sites/85broads/2014/01/06/six-no vel-machi nelearning-applications/)

HO, Rocky (2012) An Introduction to 6 Machine Learning Models. En: DZone (consulta: 12 de Septiembre de 2014) (http://architects.dzone.com/articles/introduction-6-machine)

HUECAS y SALVACHÚA (2010) Filtros Colaborativos y Sistema de Recomendación. Presentación PowerPoint. (Consulta: 24 de agosto de 2014) (http://es.slideshare.net/ghuecas/filtros-colaborativos-y-sistemas-de-recomendacin) IBAÑEZ, Felipe (2011) Métodos de Agrupamiento en el cálculo de distancias entre usuarios en un Sistema de Recomendación basado en Algoritmos de Filtrado Colaborativo. (consulta: 04 de Septiembre de (http://earchivo.uc3m.es/bitstream/handle/10016/12387/PFC_Felipe_Ibanez_Vazquez.pdf?sequenc $\mathrm{e}=1)$

IEEE, Machine Learning Applications in Speech Processing (2014) http://www.ieeglobalsip.org/symposium/mlasp.html (Consulta: 28 de Agosto 2014) Introducción a Data Mining (http://halweb.uc3m.es/esp/Personal/personas/jmmarin/esp/DM/introduccion-DM.pdf) (Consulta: 02 de Julio del 2014)

JENSEN, David y NEVILLE, Jennifer (2002) Data Mining in Social Networks Computer Science Department Faculty Publication Series. Paper 67

KUMAR, Surjeet; BHARADWAJ, Brijesh; PAL Saurabh (2012) Data Mining Applications: A comparative Study for Predicting Student's performance, pp 13-19. En: International Journal Of Innovative Technology \& Creative Engineering vol. 1, No.1 
LINOFF, Gordon S. y BERRY, Michael J.A. (2011) Data Mining Techniques for marketing, sales, and customer relationship management. Indianapolis: Wiley Publishing.

LISPWORKS (2014) Machine Learning Engine (consulta: 12 de Septiembre) (http://www.lispworks.com/success-stories/brs-mle.html)

MATHWORKS (2014) Aprendizaje Supervisado (Machine Learning) de flujo de trabajo y $\begin{array}{lllll}\text { Algoritmos } & \text { (consulta: } & \text { de } & \text { Septiembre) }\end{array}$ (http://www.mathworks.com/help/stats/supervised- learning-machine- learning-workflowand-algorithms.html)

MICROSOFT (2014) http//msdn.microsoft.com/es-es/library/bb510516.aspx (Consulta: 21 de Agosto 2014)

OLADIPUPO, Taiwo (2014) Types of Machine Learning Algorithms (consulta: $10 \mathrm{de}$ Septiembre) (http://cdn.intechopen.com/pdfs-wm/10694.pdf)

Plagatux (2008) (http://plagatux.es/wp-content/uploads/2008/04/python-logo.png) Sitio web que contiene la imagen (consulta: 10 de octubre del 2014)

PRIETO, Oscar (2010) (http://www.infor.uva.es/ isaac/doctorado/AprendizajeBayesiano.pdf) Aprendizaje Bayesiano. Presentación en power point a la cual pertenece la imagen. Presentació (consulta: 10 de septiembre del 2014)

Q. A. AI-RADAIDEH, E. M. AI-SHAWAKFA, and M. I. AI-NAJJAR, "Mining Student Data using Decision Trees", International Arab Conference on Information Technology(ACIT'2006), Yarmouk University, Jordan, 2006

RFI english (2012) (http://www.english.rfi.fr/americas/20121215-kaggle-makes-datascience-sport) Sitio web que contiene la imagen de Kaggle. (Consulta: 28 de septiembre) RODRIGUEZ, Oldemar (2013) Validación Cruzada (cross-validation) y remuestreo (bootstraping). Presentación PowerPoint (econsulta: 16 de Septiembre de 2014) (http://www.oldemarrodriguez.com/yahoo_site_admin /assets/docs/Presentaci\%C3\%B3 n__CV.293124233.pdf)

SANCHEZ, Francesc (2013) El algoritmo de series temporales. En: DBA Business Analytics (consulta: 29 de Agosto de 2014) (http://fran cescsanchezbi. webnode.es/news/e1algoritmo-de-series-temporales/)

SERVENTE y GARCÍA-MARTÍNEZ (2003) Algoritmos TDIDT Aplicados a la Minería de Datos Inteligente (consulta: 27 de agosto de 2014) (http//laboratorios.fi.uba.ar/lsi/R-ITB A26-datamining.pdf) 
SINGH, Dashmesh (2014) http//dash10mesh.blogspot.in/2014/05/difference-betwee ndata-mining-and.html (Consulta: 22 de Agosto 2014)

SOLANO, Braulio (2012) Tareas de la minería de datos: reglas de asociación y secuencias. Presentación PowerPoint (consulta: 05 de Septiembre de 2014) (http://bsolano.com/ecci/claroline/backends/download.php/UHJlc2VudGFjaW9uZXMvNy 5fVGFyZWFzX2R1X2xhX21pbmVy7WFfZGVfZGF0b3MsX3J1Z2xhc19kZV9hc29jaWFj afNuLnBkZg\%3D\%3D?cidReset=true \&cidReq=CI2352)

SOLARES, Cristina y SANZ, Ana (2007) Bayesian Networks in the Classification of Multispectral and Hyperspectral Remote Sensing Images (consulta: 28 de Agosto de 2014) (http://www.wseas.us/e-library/conferences/2007venice/papers/570-343.pdf)

SPRINGER (2014) Fundamentals of Machine Learning (consulta: 12 de Septiembre) (http://www.springer.com/cda/content/document/cda_downloaddo cument/9781447155706-c2.pdf?SGWID=0-0-45-1432520-p175474383)

SU, Xiaoyuan y KHOSHGOFTAAR, Taghi (2009) A Survey of Collaborative Filtering Techniques. En: Advances in Artificial Intelligence. (consulta: 02 de Septiembre de 2014) (http:/www.hindawi.com/journals/aai/2009/421425/)

SUCAR, Enrique (2011) Métodos de Inteligencia Artificial. Presentación PowerPoint (consulta: 05 de septiembre de 2014) (http $/ /$ ccc.inaoep.mx/ esucar/Clases-MetIA/MetIA16.pdf)

TYLER, sara, ZHANG, Yi (2013) Open Domain Recommendation: Social networks and collaborative filtering (consulta: 09 de octubre 2014)

Universidad Carlos III de Madrid (2012) (http://www.it.uc3m.es/jvillena/irc/practicas) Sitio web que contiene la imagen (consulta: 10 de octubre del 2014)

UNIVERSIDAD COMPLUTENSE MADRID (UCM) (2000) Análisis de regresión lineal: El procedimiento Regresión Lineal (consulta: 27 de agosto de 2014) (http://pend ientedemigracion.ucm.es/info/socivmyt/paginas/D_ departamento/materiales/analisis_datosyMultivariable/18reglin_SPSS.pdf)

VIALARDI, A Data Mining Approach to Recommend Learning Paths based on Academic Performance.

WIKIPEDIA

http://en.wikipedia.org/wiki/Machine_learning\#Machine_learning_and_data_mining

(Consulta: 22 de Agosto 2014)

WITTEN, Ian, HOLMES, Geoffrey y FRANK Eibe (2011) Data Mining: Practical Machine Learning Tools and Techniques. Burlington: Elsevier. 
ZHENG, Fei y WEBB, Geoff (2014) Tree Augmented Naive Bayes. En: SpringerReference

(consulta:

28

de

Agosto)

(http://www.springerrefer

ence.com/docs/html/chapterdbid/179562.html)

ZHENG, Fei y WEBB, Geoff (2014) Tree Augmented Naive Bayes. En: SpringerReference

(consulta:

28

de

Agosto)

(http://www.springerrefer

ence.com/docs/html/chapterdbid/179562.html) 